\title{
High Performance Efficiency of Distributed Optical Fiber Raman Amplifiers for Different Pumping Configurations in Different Fiber Cable Schemes
}

\author{
${ }^{1}$ Abd El-Naser A. Mohamed, ${ }^{2}$ Ahmed Nabih Zaki Rashed, ${ }^{3}$ Mahmoud M. A. Eid \\ ${ }^{1,2,3}$ Electronics and Electrical Communication Engineering Department \\ Faculty of Electronic Engineering, Menouf 32951, Menoufia University, EGYPT
}

\begin{abstract}
Fiber Raman amplifiers (FRAs) are attractive for ultra wide dense wavelength division multiplexing (UW-DWDM) transmission systems due to their advantages of broad amplification bandwidth and flexible central wavelength. With recent developments of optical pump sources with high power near $1.4 \mu \mathrm{m}$ wavelength and highly nonlinear fiber having a peak effective Raman gain coefficient more than ten times that of conventional single mode fiber, distributed FRAs (DFRAs) are emerging as a practical optical amplifier technology, especially for opening new wavelength windows such as the short and ultra long wavelength bands. Optical pump powers required for Raman amplification were significantly higher than that for Erbium doped fiber amplifier (EDFA), and the pump laser technology could not reliably deliver the required powers. However, with the improvement of pump laser technology Raman amplification is now an important means of expanding span transmission reach and capacity. In the present paper, we have deeply investigated the proposed model for optical distributed fiber Raman amplifiers in the transmission signal power and pump power within Raman amplification technique in co-pumped, counter-pumped, and bi-directional pumping direction configurations through different types of fiber cable media. The validity of this model was confirmed by using experimental data and numerical simulations.
\end{abstract}

Keywords: Distributed fiber Raman amplifier, Signal power, Pumping power, Forward pumping, Different fiber media, Backward pumping, and Bidirectional pumping configuration.

\section{Introduction}

The first fiber optical telecommunication systems emerged with the engineering of low loss optical fiber [1] Even though the complexity of the system has increased, the basic elements remain the same. They consist of an optical source, a means of modulating the source, the transmission medium (i.e., the optical fiber), and a detector at the output end of the fiber. Fiber loss is one limitation to the transmission distance of this system. In the early days of fiber-optic communications the loss of the fiber was compensated for in long spans by using electrical regenerators. As their name implies, these devices detected the signal, converted it to an electrical signal, and using a new laser transmitted a new version of the signal. Electrical regenerators were expensive and also limited the rate at which data could be transmitted as time for the much slower electrical processing to occur had to be built into the system. In order to overcome the limitations imposed by electrical regeneration, a means of optical amplification was sought. Two competing technologies emerged: the first was erbium-doped fiber amplifiers (EDFA) [2, 3] and the second Raman amplification [4]. In the first deployed systems EDFA emerged as the preferred approach. One reason was that the optical pump powers required for Raman amplification were significantly higher than that for EDFA, and the pump laser technology could not reliably deliver the required powers. However, with the improvement of pump laser technology Raman amplification is now an important means of expanding span transmission reach and capacity [5].

In a multiple wavelength telecom system it is important that all signal wavelengths have similar optical powers. The variation in the gain provided to different wavelengths after passing through an amplifier is referred to as the gain flatness. If the signal at one wavelength is disproportionately amplified, as it passes through several amplifiers, it will grow super linearly relative to the other channels reducing the gain to other channels [6]. The system, however, will still be limited by the channel with the lowest gain. As a result, after each amplifier the gain spectrum generally is flattened. One approach is to insert wavelength-dependent lossy elements, within the amplifier, with the appropriate spectral profile. Raman amplification offers the ability to achieve this without lossy elements. In Raman amplification a flat spectral profile can be obtained by using multiple pump wavelengths [7, 8]. For a given fiber the location of the Raman gain is only dependent on the wavelength of the pump, the magnitude of the gain is proportional to the pump power, and the shape of the gain curve is independent of the pump wavelength. Therefore, if multiple pumps are used a flat spectral gain profile can be obtained [9]. The required pump wavelengths and the gain required at each wavelength can be predicted by summing the logarithmic gain profiles at the individual pump wavelengths [10].

In the present study, we have deeply analyzed the signal power, pumping power, rate of change of signal,

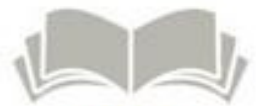


pumping powers with respect to transmission distance under the variations of signal, pump powers and signal and pump wavelengths for different fiber link media in different pumping direction configurations (forward, backward, and bi-directional) over wide range of the operating parameters.

\section{Modeling Analysis}

Signals fad with distance when they traveling through any type of media. As the optical signal moves along a SMF, it gets attenuated along the fiber. The signal power when it travels through the distance $\mathrm{z}$ without any amplification, $\mathrm{P}_{\mathrm{sWNA}}$ can be expressed as following:

$$
P_{S W N A}(z)=P_{s o} \exp \left(-\alpha_{L S} z\right)
$$

Systems avoid this problem by amplifying signals along the way. So there is a need for using optical fiber amplifiers. The evolution of the input signal power $\left(\mathrm{P}_{\mathrm{s}}\right)$ and the input pump power $\left(\mathrm{P}_{\mathrm{p}}\right)$ propagating along the single mode optical fiber in watt; can be quantitatively described by different equations called propagation equations. The rate of change of signal and pump power with the distance $\mathrm{z}$, can be expressed as mentioned in [11]:

$$
\begin{aligned}
\frac{d P_{p}}{d z} & =-\alpha_{L p} P_{p}(z)-\frac{\lambda_{s}}{\lambda_{p}} g_{\operatorname{Re} f f} P_{s}(z) P_{p}(z) \\
\frac{d P_{s}}{d z} & =-\alpha_{L s} P_{s}(z)+\frac{\lambda_{s}}{\lambda_{p}} g_{\operatorname{Re} f f} P_{S}(z) P_{p}(z)
\end{aligned}
$$

Where $\lambda_{\mathrm{s}}$ and $\lambda_{\mathrm{p}}$ are the signal and pump wavelengths in $\mu \mathrm{m}$ respectively, $\mathrm{z}$ is the distance in $\mathrm{km}$ from $\mathrm{z}=0$ to $\mathrm{z}=\mathrm{L}$, $\alpha_{\mathrm{Ls}}$ and $\alpha_{\mathrm{Lp}}$ are the linear attenuation coefficient of the signal and pump power in the optical fiber in $\mathrm{km}^{-1}$ respectively, The linear attenuation, $\alpha_{\mathrm{L}}$ can be expressed as:

$$
\alpha_{L}=\alpha / 4.343
$$

Where $\alpha$ is the attenuation coefficient in $d B / \mathrm{km}$. $g_{\text {Reff }}$ is the Raman gain efficiency in $\mathrm{W}^{-1} \mathrm{~km}^{-1}$ of the fiber cable length, $\mathrm{L}$ in $\mathrm{km}$, which is a critical design issue and is given by the following equation:

$$
\mathrm{g}_{\text {Reff }}=\frac{g_{R}}{A_{\text {eff }} \times 10^{-18}}
$$

Where $\mathrm{g}_{\mathrm{R}}$ is the maximum Raman gain in $\mathrm{km} \mathrm{W}^{-1}, \mathrm{~A}_{\text {eff }}$ the effective area of the fiber cable used in the amplification in $\mu \mathrm{m}^{2}$. Equation (1) can be solved when both sides of the equation are integrated. When using forward pumping, the pump power can be expressed as the following expression [12]:

$$
P_{P F}(z)=P_{p o F} \exp \left(-\alpha_{L p} z\right)
$$

Where $\mathrm{P}_{\mathrm{PoF}}$, is the input pump power in the forward direction in watt at $\mathrm{z}=0$.

In the backward pumping the pump power is given by [13]:

$$
P_{P B}(z)=P_{p o B} \exp \left\lfloor-\alpha_{L p}(L-z)\right\rfloor
$$

Where $\mathrm{P}_{\mathrm{PoB}}$, is the input pump power in the backward direction in watt at $\mathrm{z}=\mathrm{L}$. In the case of bi-directional pump both of the pump can be equal or different in the used wavelength or the used amount of power, therefore in this case the following equation can be used to calculate the pump power at point $\mathrm{z}[14]$ :

$$
\left.\left.P_{P F B}(z)=(r f) P_{p o F} \exp -\alpha_{L p} z\right)+(1-r f) P_{p o B} \exp -\alpha_{L p}(L-z)\right]
$$

Where $r_{f}$ is the percentage of pump power launched in the forward direction. If the values of $\mathrm{P}_{\mathrm{P}}$ are substituted in differential Eq. (2), and is integrated from $\mathrm{z}=0$ to $\mathrm{z}=\mathrm{L}$ for the signal power in the forward and the backward pumping the result mathematical equation can be written as mentioned in [13]:

$$
P_{S}(z)=P_{s o} \exp \left[\left(\frac{g_{R}}{A_{e f f}}\right) P_{p o} L_{e f f}-\alpha_{L s} z\right]
$$

where $\mathrm{P}_{\mathrm{so}}$ and $\mathrm{P}_{\mathrm{po}}$ denotes to the input signal and pump power respectively. This means that $\mathrm{P}_{\mathrm{po}}=\mathrm{P}_{\mathrm{poF}}$ in case of forward pump and $\mathrm{P}_{\mathrm{po}}=\mathrm{P}_{\mathrm{poB}}$ in case of backward pump, and $\mathrm{L}_{\mathrm{eff}}$, is the effective length in $\mathrm{km}$, over which the nonlinearities still holds or SRS occurs in the fiber and is defined as [15]:

$$
L_{\text {eff }}=\frac{1-\exp \left(-\alpha_{L p} z\right)}{\alpha_{L p}}
$$

Recently, there have been many efforts to utilize fiber Raman amplifier (FRA) in long-distance, high capacity WDM systems. This is mainly because FRA can improve the optical signal to noise ratio (OSNR) and reduce the impacts of fiber nonlinearities [16].

\section{Simulation Results and Analysis}

\begin{tabular}{|c|c|c|}
\hline $\begin{array}{l}\text { Operating } \\
\text { parameter }\end{array}$ & Symbol & Value \\
\hline $\begin{array}{l}\text { Operating } \\
\text { signal } \\
\text { wavelength }\end{array}$ & $\lambda_{\mathrm{s}}$ & $1.45 \leq \lambda_{\mathrm{s}}, \mu \mathrm{m} \leq 1.65$ \\
\hline $\begin{array}{l}\text { Operating } \\
\text { pump } \\
\text { wavelength }\end{array}$ & $\lambda_{\mathrm{p}}$ & $1.40 \leq \lambda_{\mathrm{p}}, \mu \mathrm{m} \leq 1.44$ \\
\hline $\begin{array}{l}\text { Input signal } \\
\text { power }\end{array}$ & $\mathrm{P}_{\mathrm{so}}$ & $0.002 \leq \mathrm{P}_{\mathrm{so}}, \mathrm{W} \leq 0.02$ \\
\hline $\begin{array}{l}\text { Input pump } \\
\text { power }\end{array}$ & $\mathrm{P}_{\mathrm{po}}$ & $0.165 \leq \mathrm{P}_{\mathrm{po}}, \mathrm{W} \leq 0.365$ \\
\hline $\begin{array}{l}\text { Percentage of } \\
\text { power }\end{array}$ & $r_{f}$ & 0.5 \\
\hline
\end{tabular}

In the present study, the optical distributed Raman amplifiers have been modeled and have been parametrically investigated, based on the coupled differential equations of first order, and also based on the set of the assumed of affecting operating parameters on the system model. In fact, the employed software computed the variables under the following operating parameters as shown in Table 1 .

Table1. Vvalues of operating parameters in proposed model.

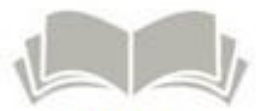




\begin{tabular}{|c|c|c|c|c|c|}
\hline $\begin{array}{l}\text { launched in } \\
\text { forward } \\
\text { direction }\end{array}$ & & & & & \\
\hline $\begin{array}{l}\text { Attenuation } \\
\text { of the signal } \\
\text { power in } \\
\text { silica-doped } \\
\text { fiber }\end{array}$ & $\alpha_{s}$ & \multicolumn{4}{|c|}{$0.25 \mathrm{~dB} / \mathrm{km}$} \\
\hline $\begin{array}{l}\text { Attenuation } \\
\text { of the pump } \\
\text { power in } \\
\text { silica-doped } \\
\text { fiber }\end{array}$ & $\alpha_{\mathrm{P}}$ & \multicolumn{4}{|c|}{$0.3 \mathrm{~dB} / \mathrm{km}$} \\
\hline \multicolumn{2}{|c|}{$\begin{array}{c}\text { Types of fiber cable } \\
\text { media }\end{array}$} & $\begin{array}{l}\text { Truewave } \\
\text { reach } \\
\text { fiber } \\
\end{array}$ & $\begin{array}{l}\text { LEAF } \\
\text { (NZ- } \\
\text { DSF) } \\
\end{array}$ & $\begin{array}{l}\text { SMF-28 } \\
\text { (NDSF) }\end{array}$ & Unit \\
\hline $\begin{array}{l}\text { Effective } \\
\text { Area }\end{array}$ & $\mathrm{A}_{\mathrm{eff}}$ & 55 & 72 & 84.95 & $(\mu \mathrm{m})^{2}$ \\
\hline $\begin{array}{l}\text { Raman Gain } \\
\text { Efficiency }\end{array}$ & $\mathrm{g}_{\text {Reff }}$ & 0.6 & 0.45 & 0.38 & $\underset{1}{(\mathrm{~W} . \mathrm{km})}$ \\
\hline
\end{tabular}

The following points of discussion will cover all operating design parameters of multiplexing/demultiplexing based optical distributed Raman amplifier device, such as, input signal power, input pumping power, operating signal wavelength, operating pump wavelength, and different fiber link media. Then based on the basic model analysis and the set of the series of the following figures are shown below, the following facts can be obtained:

\section{1. Variations of the output pumping power, $P_{p}$}

Variation of the output pumping power, $P_{p}$ is investigated against variations of the controlling set of parameters as displayed in Figs. (1-4), these figures clarify the following results:

a- In case of forward direction:

i. As distance $\mathrm{z}$ increases, the output pumping power decreases exponentially.

ii. For certain value of distance $\mathrm{z}$, with increasing the initial pumping power, the output pumping power also will increase.

b- In case of backward direction:

i. As distance $\mathrm{z}$ increases, the output pumping power increases exponentially.

ii. For certain value of distance $z$, with increasing the initial pumping power, the output pumping power also will increase.

c- In case of bi-directional:

i. For $\mathrm{z} \leq 50 \mathrm{~km}$, the output pumping power decreases exponentially, and for $\mathrm{z} \geq 50$ $\mathrm{km}, \mathrm{P}_{\mathrm{pFB}}$ increases exponentially.

ii. For certain value of distance $z$, with increasing the initial pumping power, the output pumping power also will increase.

\section{2. Variations of the output signal power, $P_{s}$}

Variation of the output signal power, $P_{s}$ is investigated against variations of the controlling set of parameters as displayed in Figs. (5-11), these figures clarify the following results:

a- Without any amplification: with increasing distance, $\mathrm{z}$, the output signal power decreases exponentially.

b- In case of forward direction:

1) For certain value of initial pumping power:

i. Initial pumping power $=0.165 \mathrm{~mW}$, for distance $\mathrm{z} \leq 2 \mathrm{~km}$, the output signal power increases exponentially, and for $\mathrm{z} \geq 2 \mathrm{~km}$, the output signal power decreases exponentially.

ii. Initial pumping power $=0.265 \mathrm{~mW}$, for distance $\mathrm{z} \leq 8 \mathrm{~km}$, the output signal power increases exponentially, and for $\mathrm{z} \geq 8 \mathrm{~km}$, the output signal power decreases exponentially.

iii. Initial pumping power $=0.365 \mathrm{~mW}$, for distance $\mathrm{z} \leq 13 \mathrm{~km}$, the output signal power increases exponentially, and for $z \geq 13 \mathrm{~km}$, the output signal power decreases exponentially.

2) For certain value of distance $z$ :

i. With increasing the initial pumping power, the output signal power also will increase.

ii. With increasing the initial signal power, the output signal power also will increase.

3) After using different media of optical fiber cable, it is indicated that the true wave reach fiber presented the best results.

c- In case of backward direction:

The results are the same as in case of forward direction.

d- In case of bi-directional:

1) For certain value of initial pumping power:

i. Initial pumping power $=0.165 \mathrm{~W}$, for distance $\mathrm{z} \leq 1 \mathrm{~km}$, the output signal power increases exponentially, for $1 \leq \mathrm{z}, \mathrm{km} \leq 50$ the output signal power decreases exponentially, and for $z \geq 50 \mathrm{~km}$, the output signal power increases exponentially again.

ii. Initial pumping power $=0.265 \mathrm{~W}$, for distance $\mathrm{z} \leq 8 \mathrm{~km}$, the output signal power increases exponentially, for $8 \leq \mathrm{z}, \mathrm{km} \leq 49$ the output signal power decreases exponentially, and for $z \geq 49 \mathrm{~km}$, the output signal power increases exponentially again.

iii. Initial pumping power $=0.365 \mathrm{~W}$, for distance $\mathrm{z} \leq 13 \mathrm{~km}$, the output signal power increases exponentially, for $13 \leq \mathrm{z}, \mathrm{km} \leq 48$ the output signal power decreases exponentially, and for $\mathrm{z} \geq 48 \mathrm{~km}$, the output signal power increases exponentially again.

2) For certain value of distance $z$ :

i. With increasing the initial signal power, the output signal power also will increase.

ii. With increasing the initial pumping power, the output signal power also will increase.

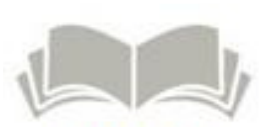


3) After using different media of optical fiber cable, it is indicated that the true wave reach fiber presented the best results.

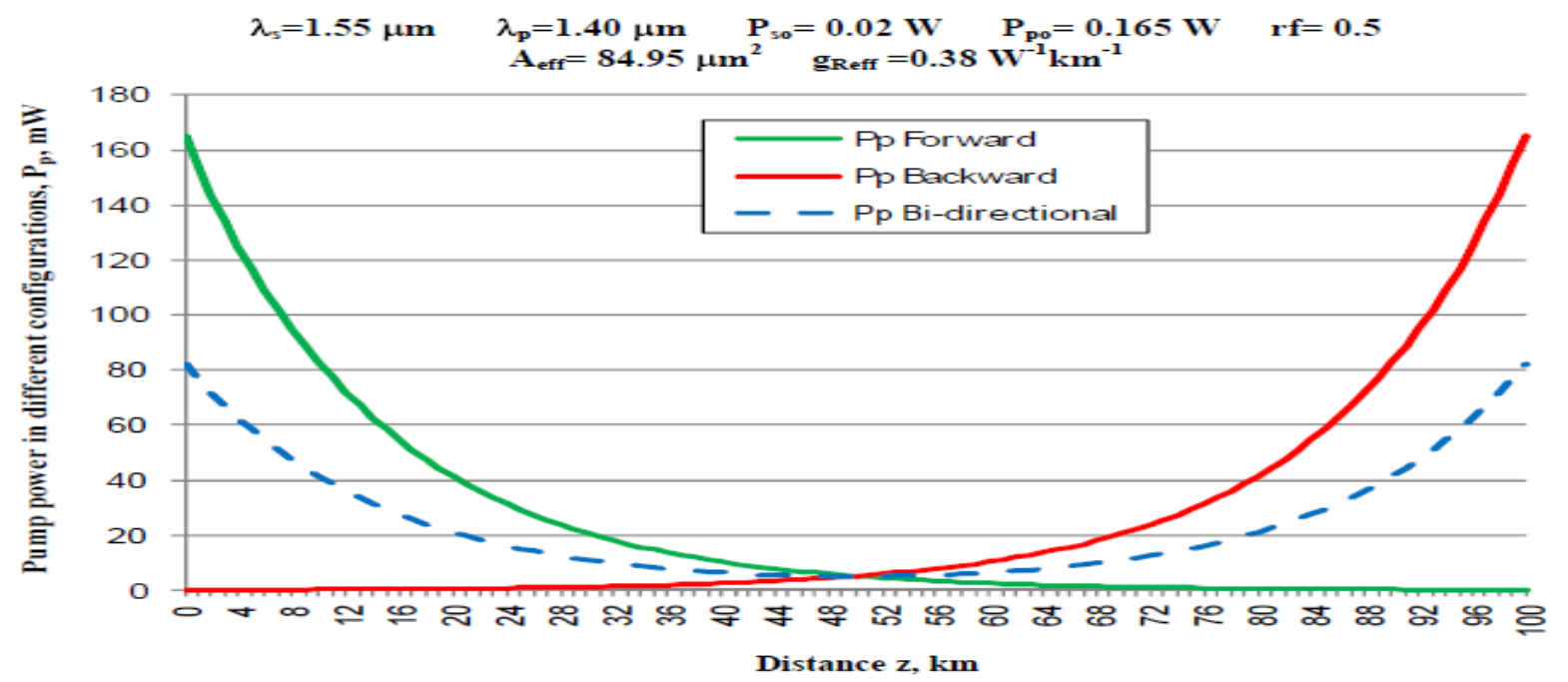

Fig. 1. Variations of pump power in different configurations against variations of distance at the assumed set of the operating parameters.

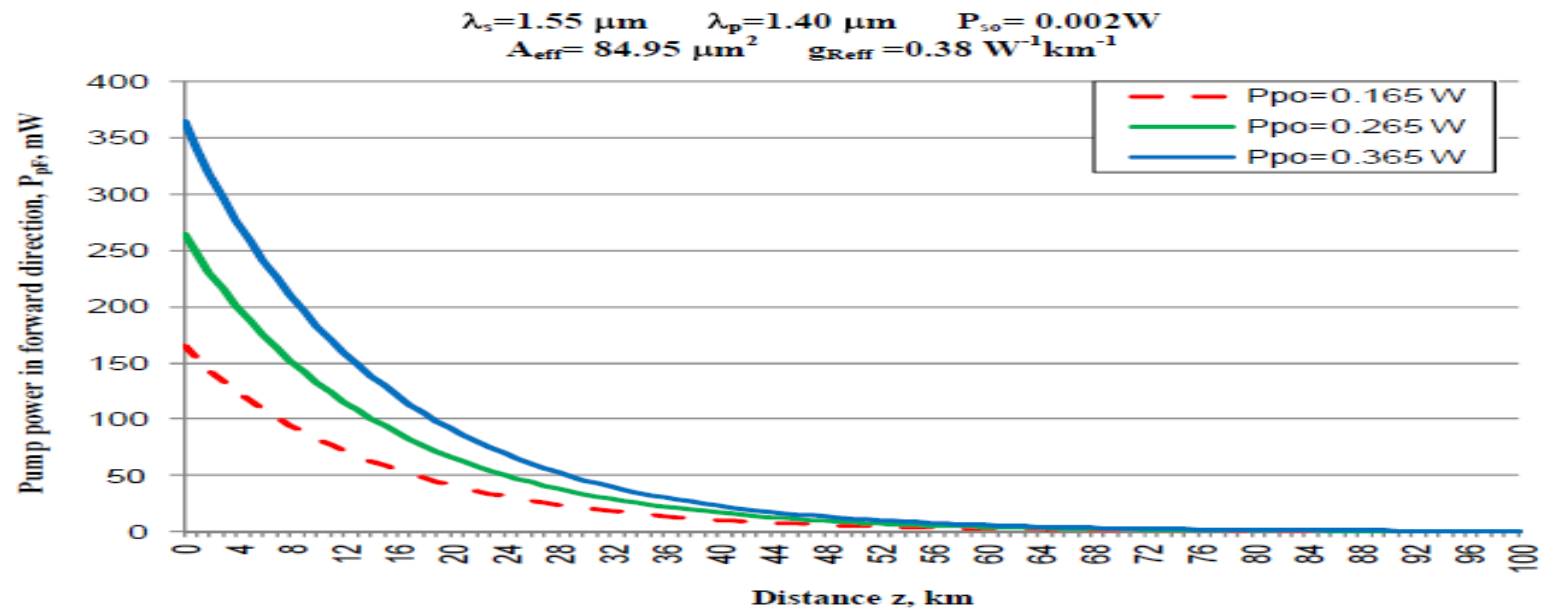

Fig. 2. Variations of pump power in forward direction against variations of distance $\mathrm{z}$ at the assumed set of the operating parameters. 
International Journal of Computer Science and Network (IJCSN)

Volume 1, Issue 1, February 2012 www.ijcsn.org ISSN 2277-5420

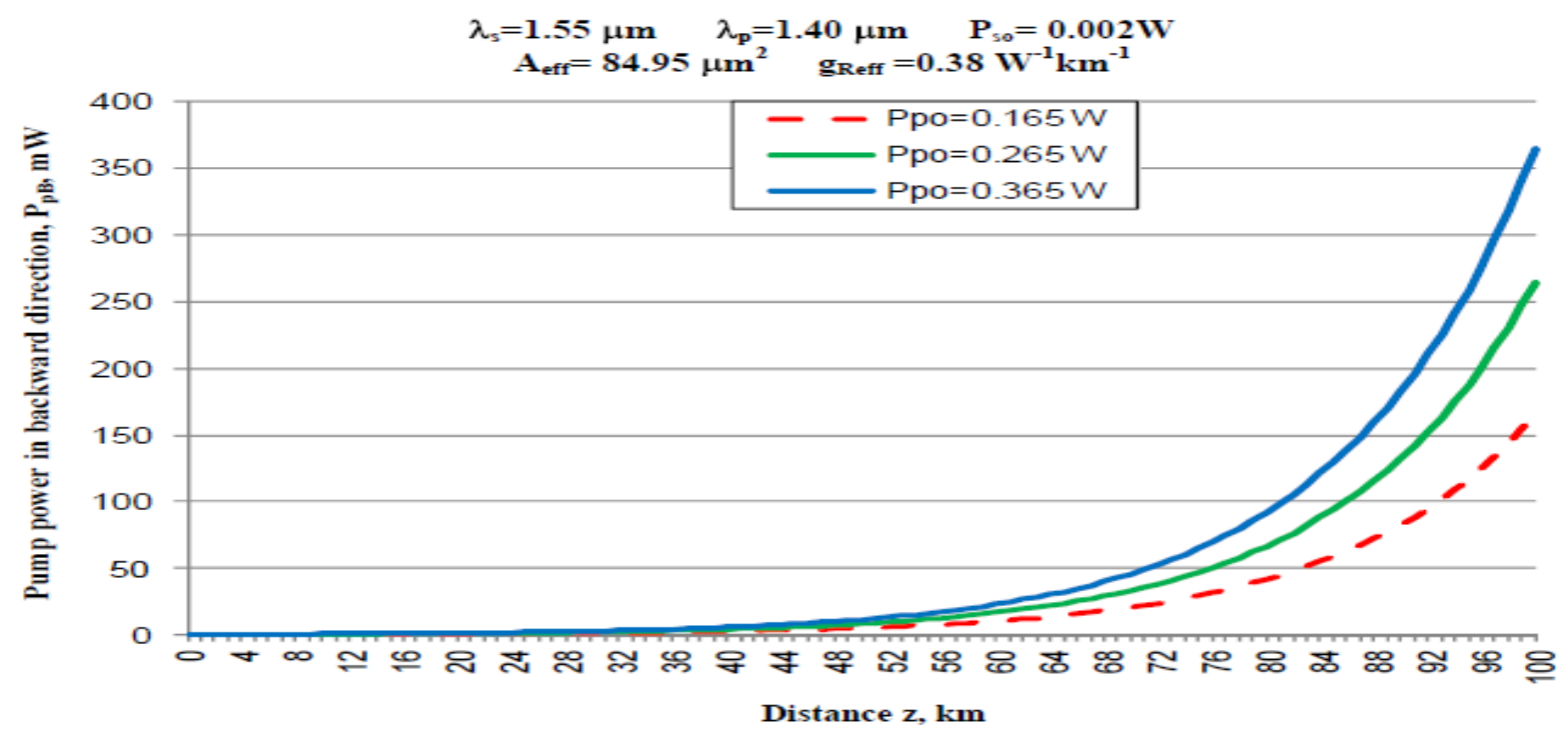

Fig. 3. Variations of pump power in backward direction against variations of distance $\mathrm{z}$ at the assumed set of the operating parameters.

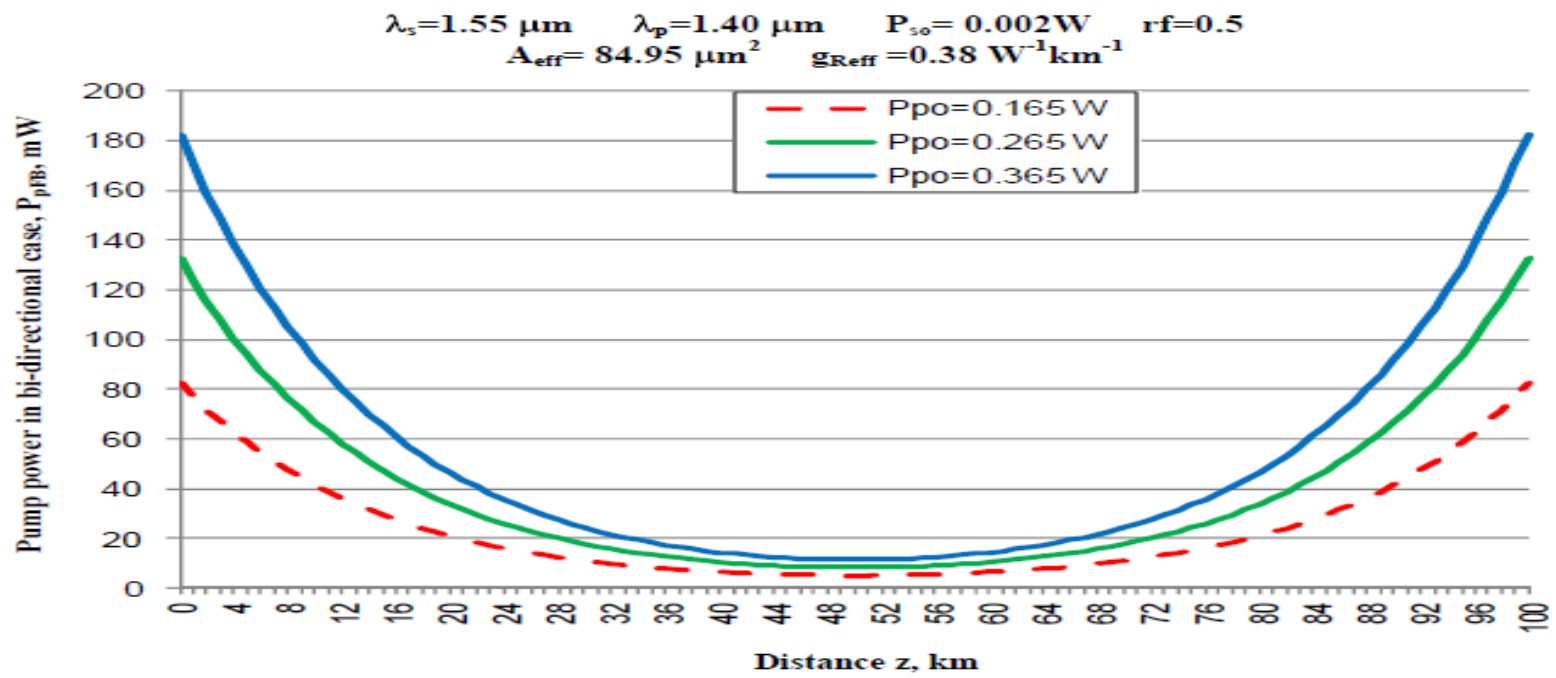

Fig. 4. Variations of pump power in bi-directional case against variations of distance $\mathrm{z}$ at the assumed set of the operating parameters. 


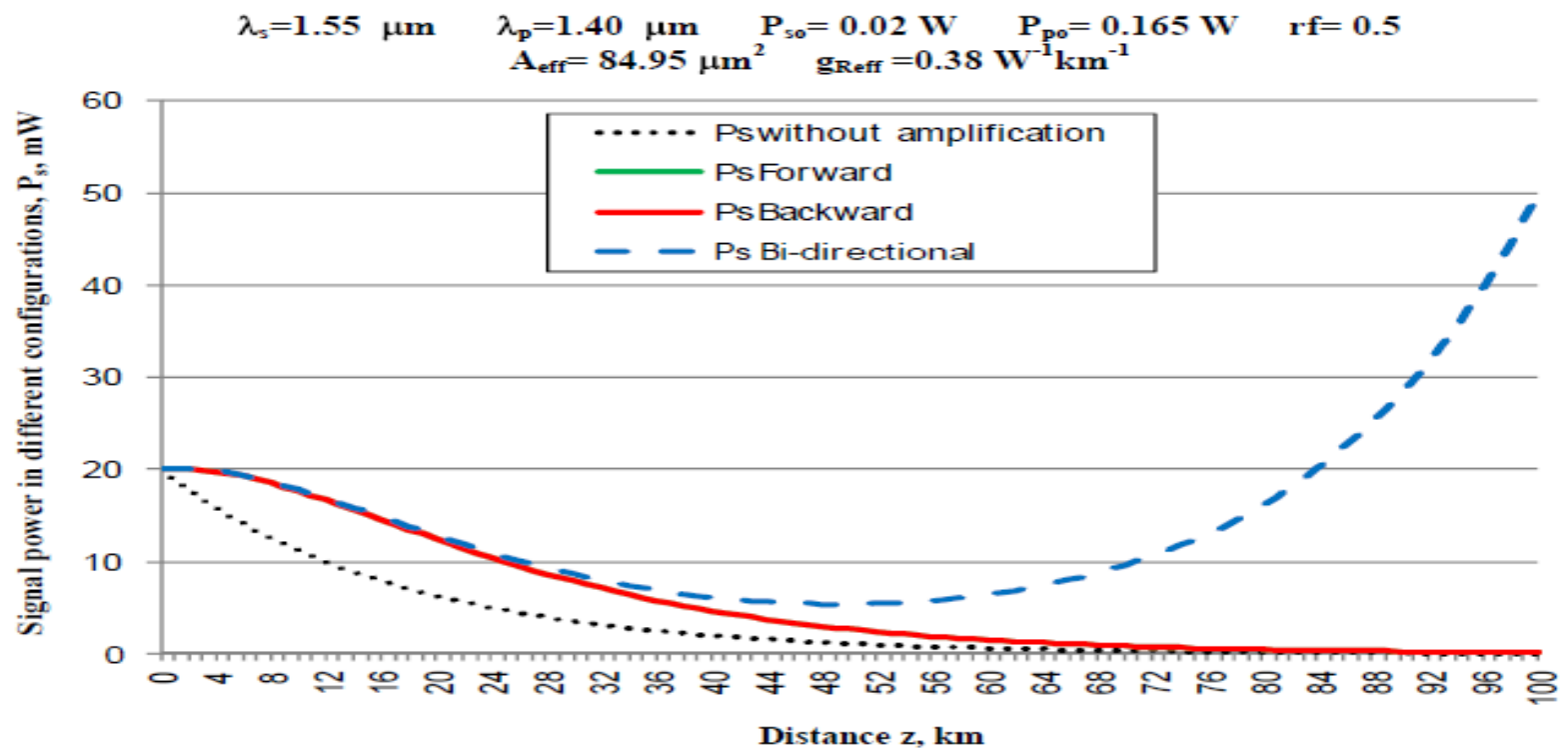

Fig. 5. Variations of signal power in different configurations against variations of distance $\mathrm{z}$ at the assumed set of the operating parameters.

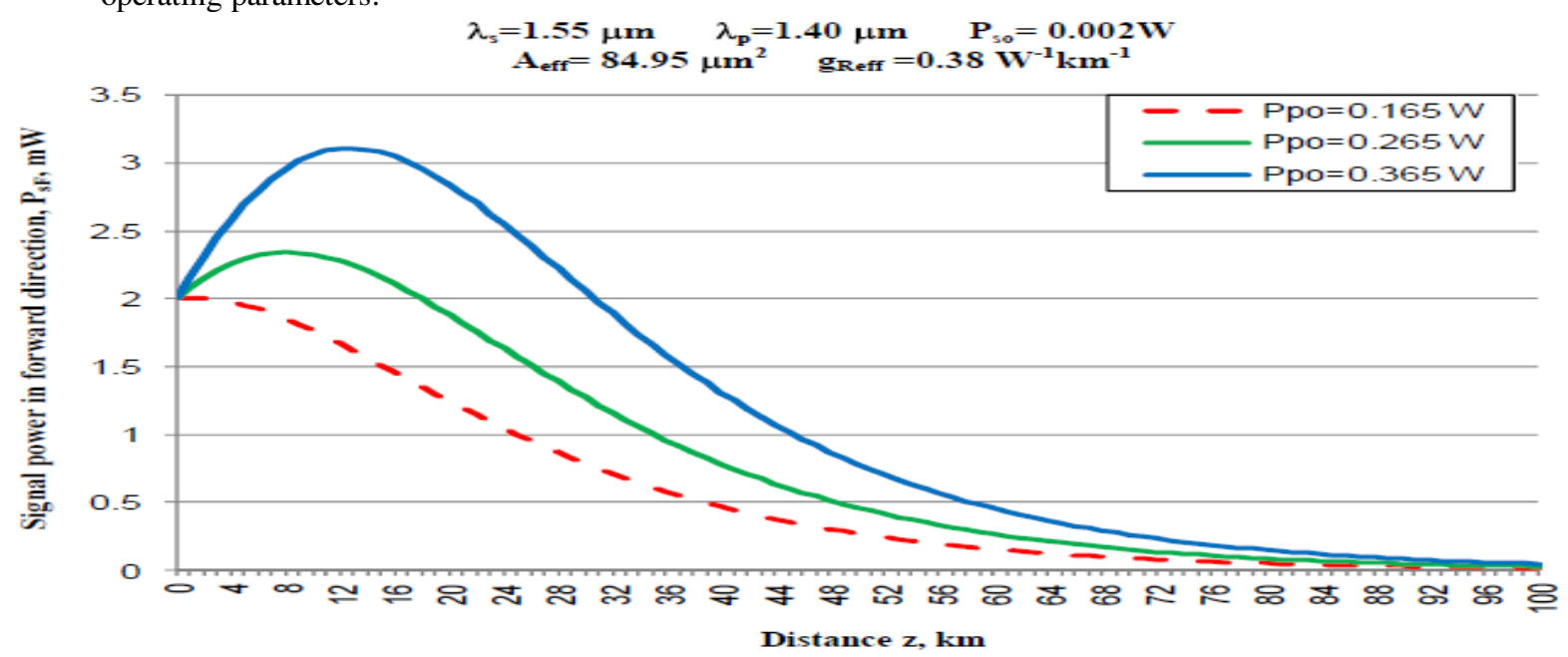

Fig. 6. Variations of signal power in forward direction against variations of distance $\mathrm{z}$ at the assumed set of the operating parameters. 
International Journal of Computer Science and Network (IJCSN)

Volume 1, Issue 1, February 2012 www.ijcsn.org ISSN 2277-5420

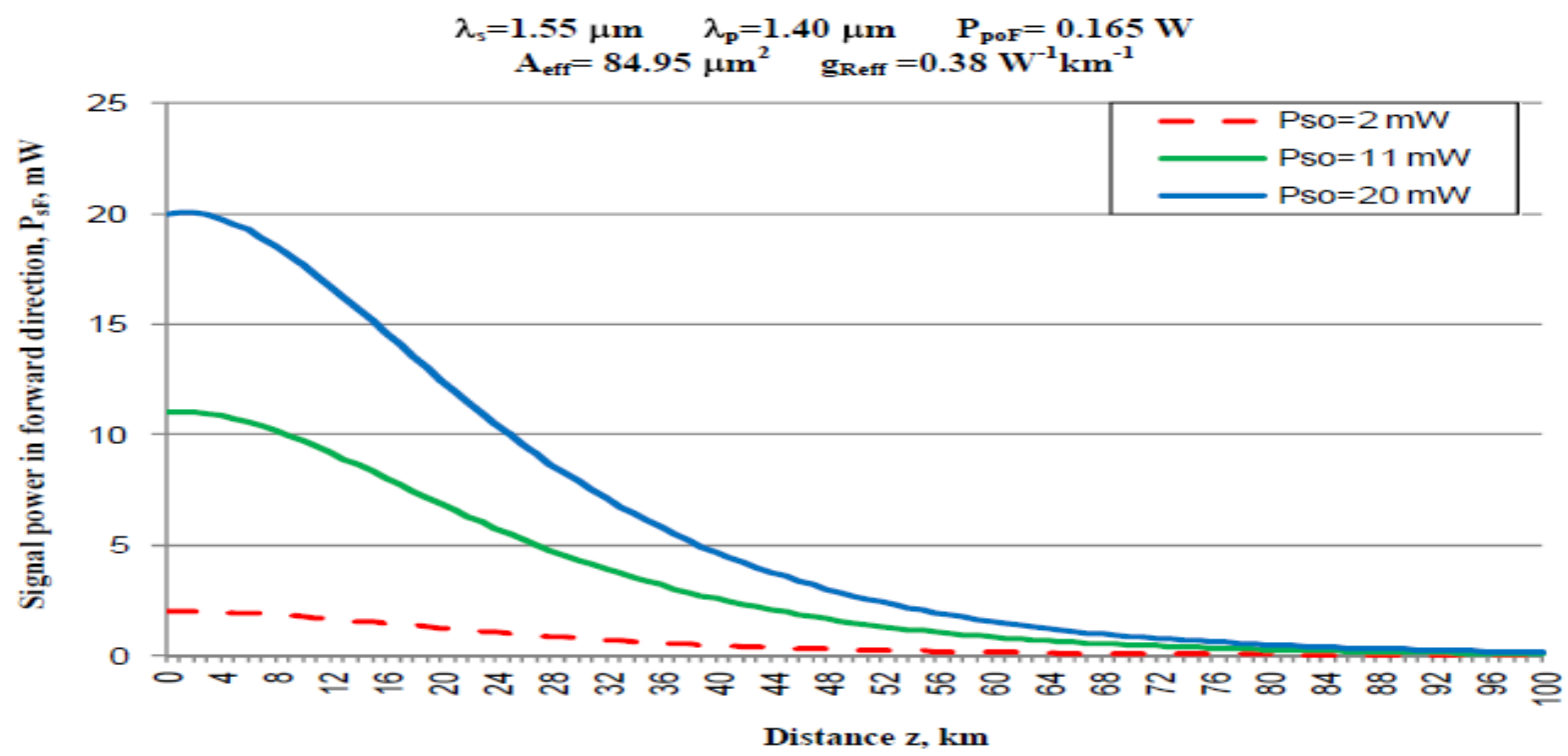

Fig. 7. Variations of signal power in forward direction against variations of distance $\mathrm{z}$ at the assumed set of the operating parameters.

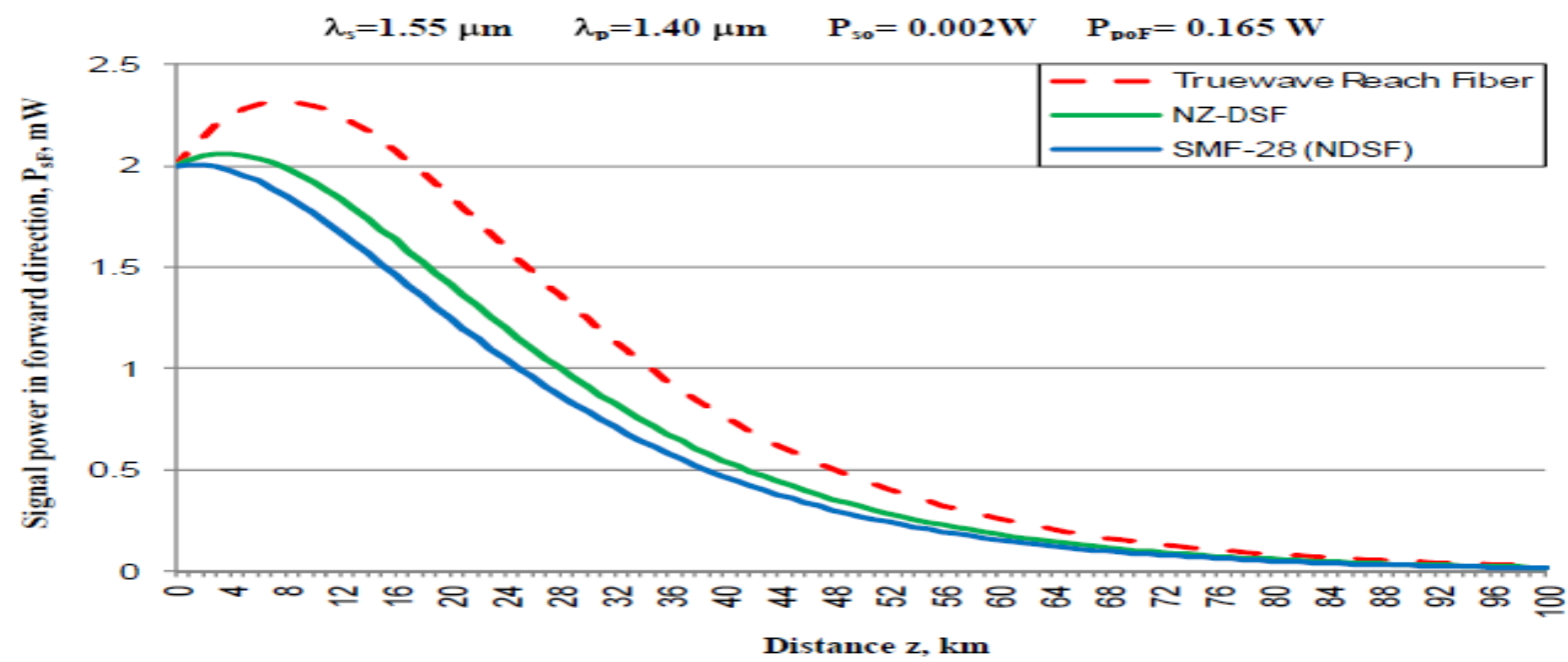

Fig. 8. Variations of signal power in forward direction against variations of distance $\mathrm{z}$ at the assumed set of the operating parameters. 
International Journal of Computer Science and Network (IJCSN)

Volume 1, Issue 1, February 2012 www.ijcsn.org ISSN 2277-5420

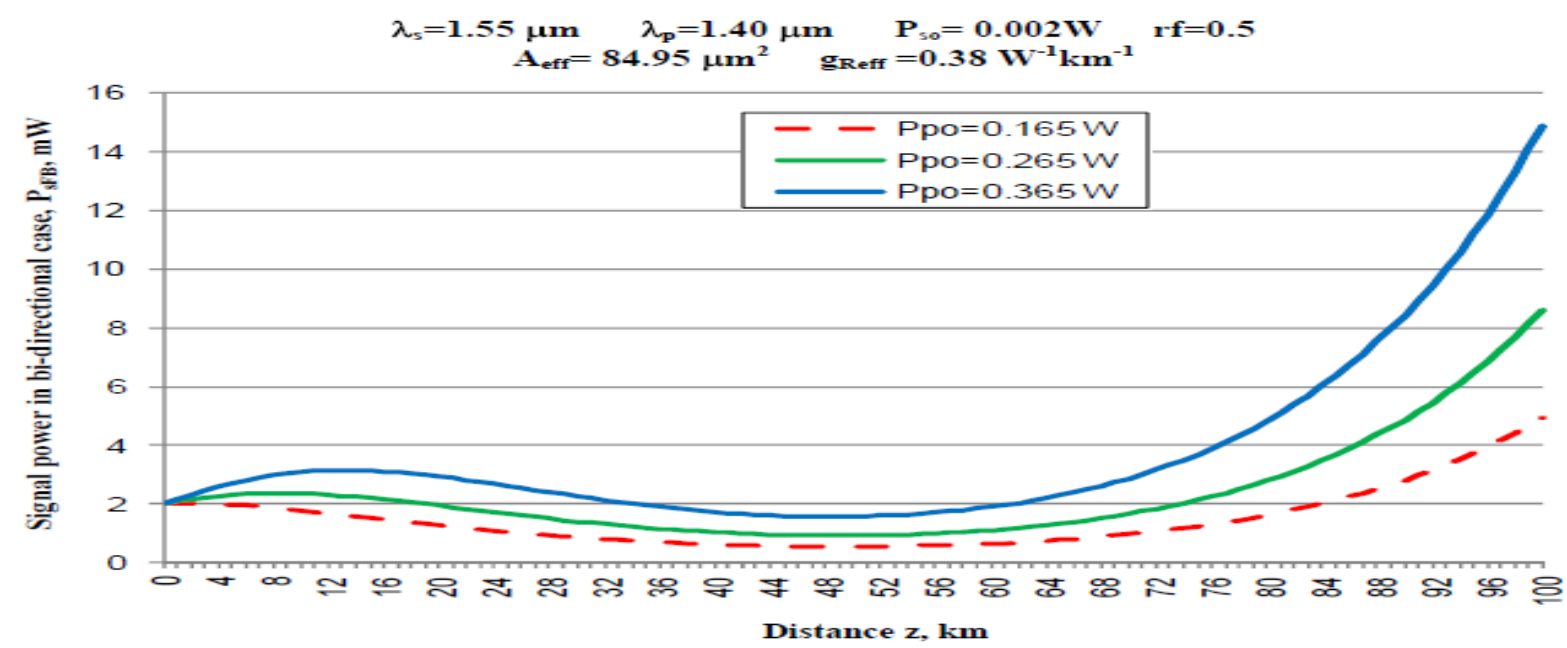

Fig. 9. Variations of signal power in bi-directional case against variations of distance $\mathrm{z}$ at the assumed set of the operating parameters.

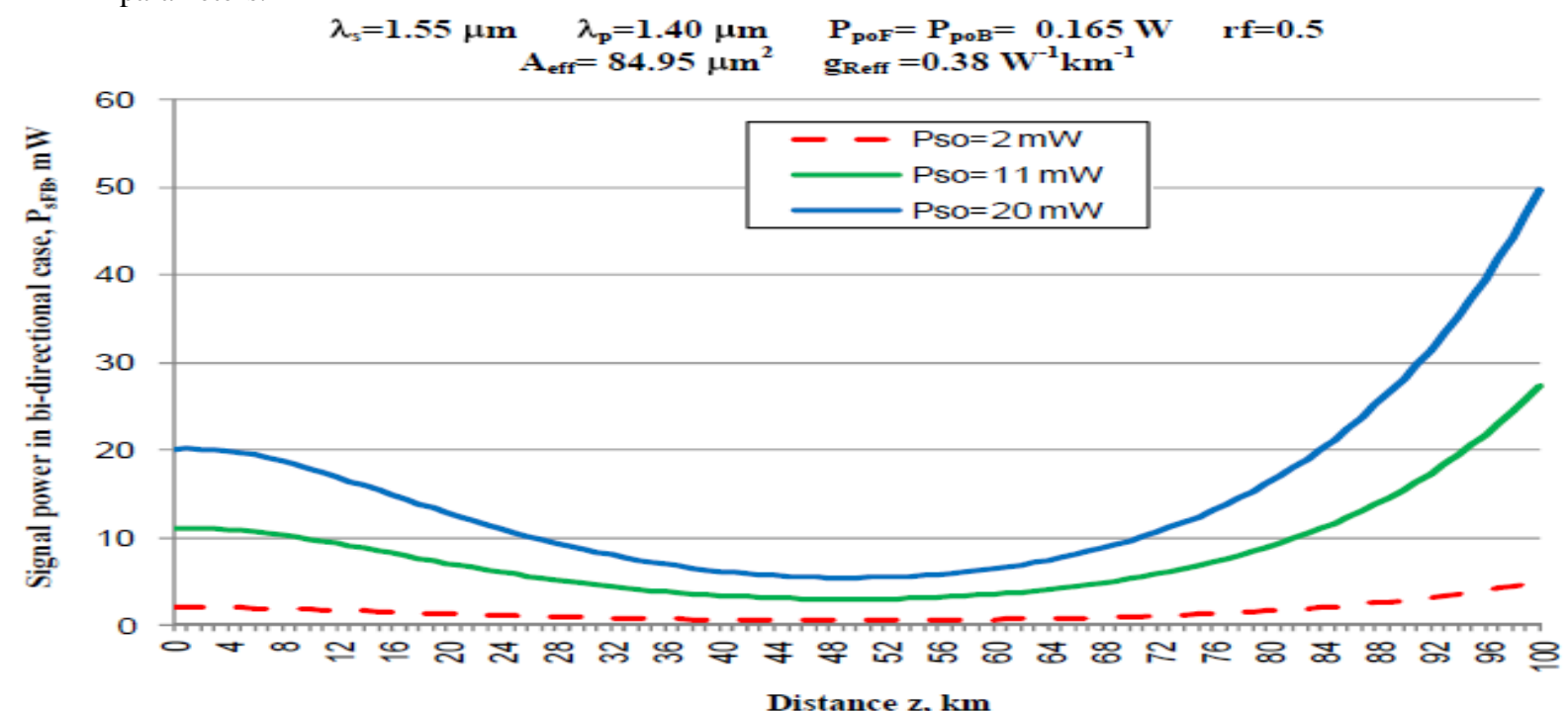

Fig. 10. Variations of signal power in case of bi-directional case against variations of distance $\mathrm{z}$ at the assumed set of the operating parameters. 
International Journal of Computer Science and Network (IJCSN)

Volume 1, Issue 1, February 2012 www.ijcsn.org ISSN 2277-5420

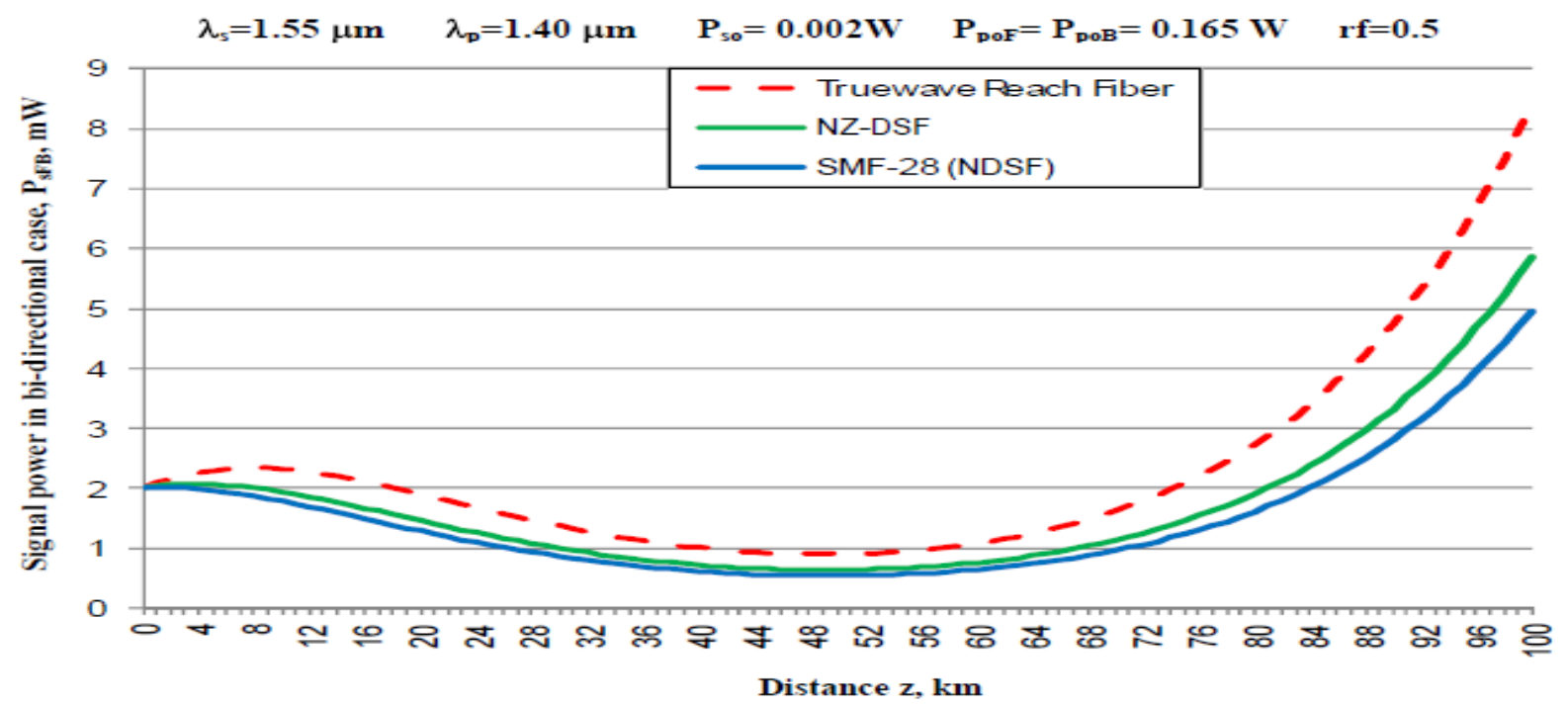

Fig. 11. Variations of signal power in bi-directional case against variations of distance $\mathrm{z}$ at the assumed set of the operating parameters.

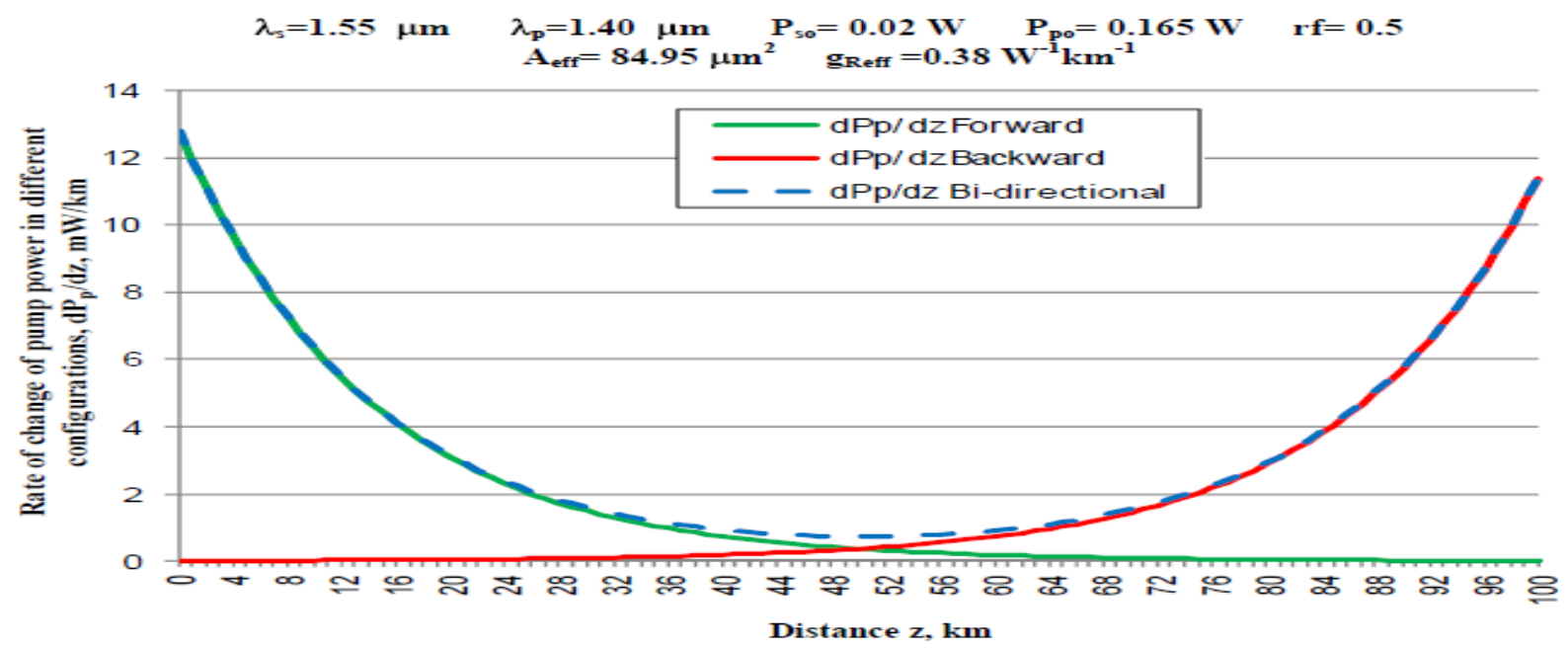

Fig. 12. Variations of rate of change of pump power in different configurations against variations of distance $\mathrm{z}$ at the assumed set of the operating parameters. 
International Journal of Computer Science and Network (IJCSN)

Volume 1, Issue 1, February 2012 www.ijcsn.org ISSN 2277-5420

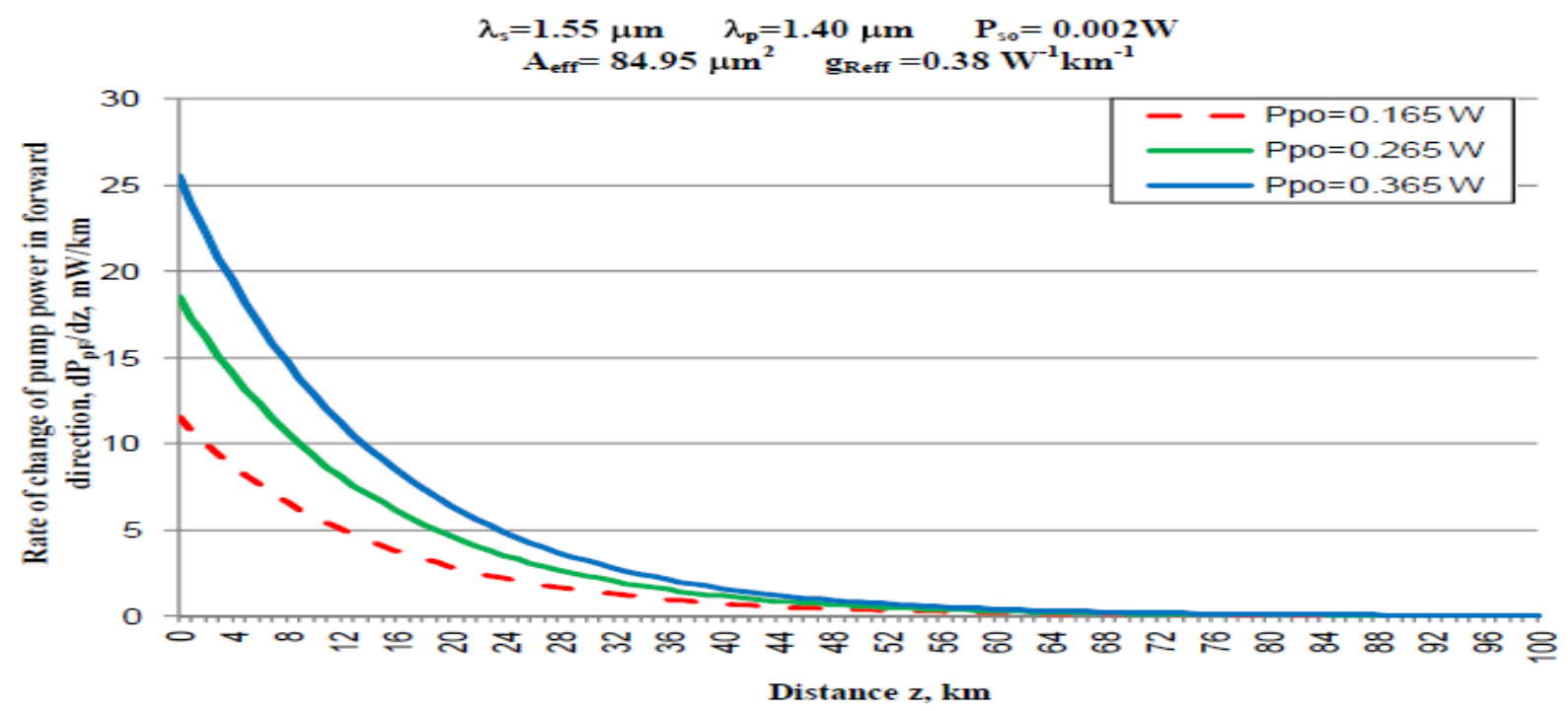

Fig. 13. Variations of rate of change of pump power in forward direction against variations of distance $\mathrm{z}$ at the assumed set of the operating parameters.

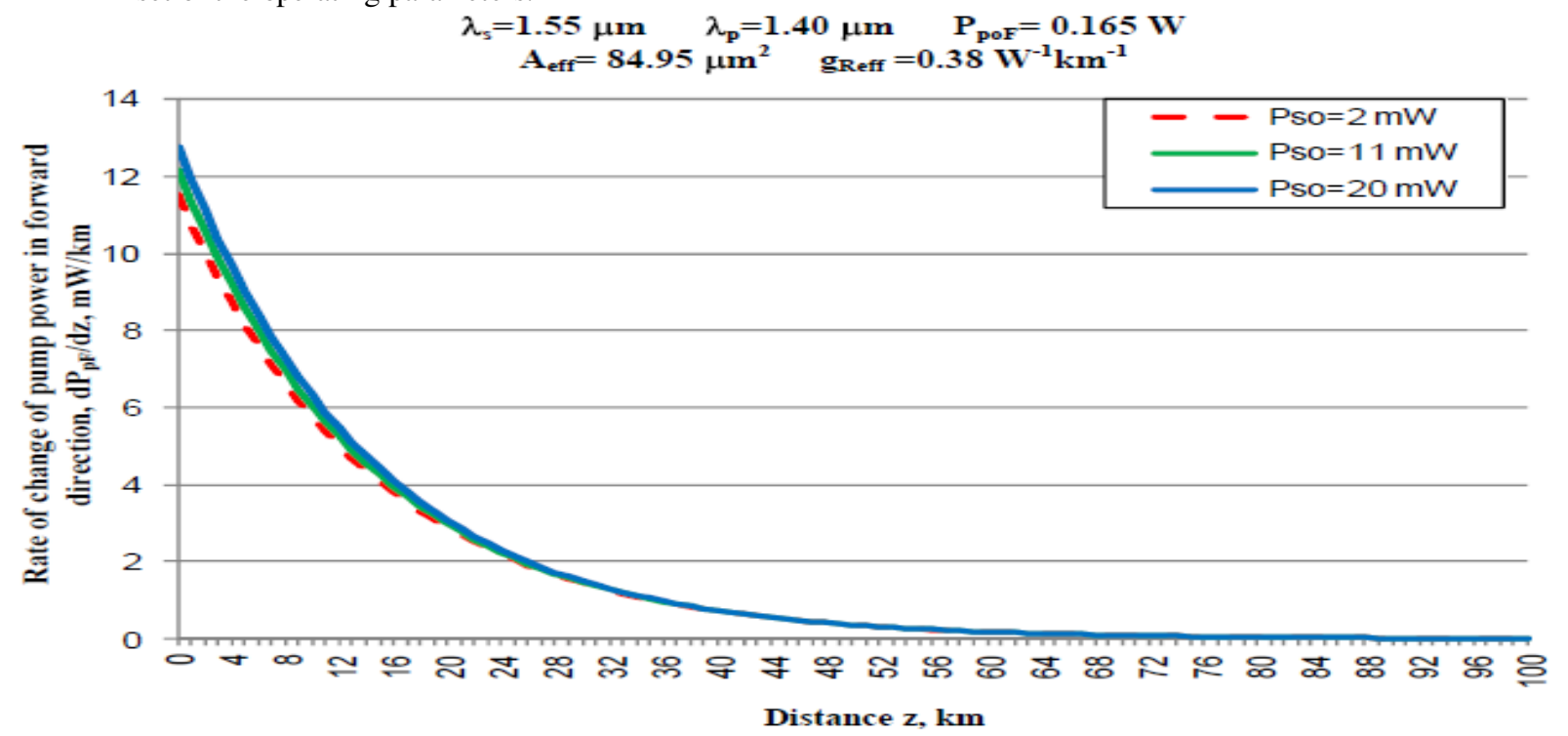

Fig. 14. Variations of rate of change of pump power in forward direction against variations of distance $\mathrm{z}$ at the assumed set of the operating parameters. 
International Journal of Computer Science and Network (IJCSN)

Volume 1, Issue 1, February 2012 www.ijcsn.org ISSN 2277-5420

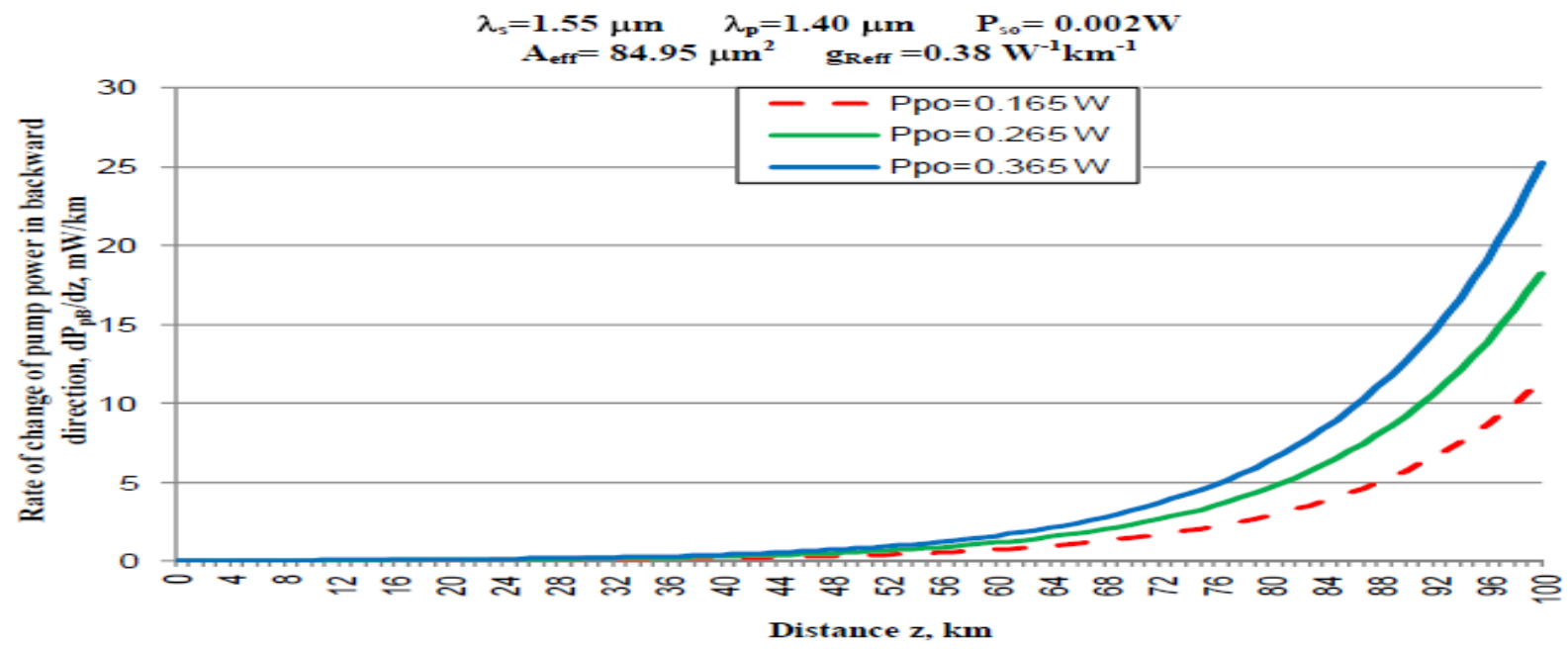

Fig. 15. Variations of rate of change of pump power in backward direction against variations of distance $\mathrm{z}$ at the assumed set of the operating parameters.

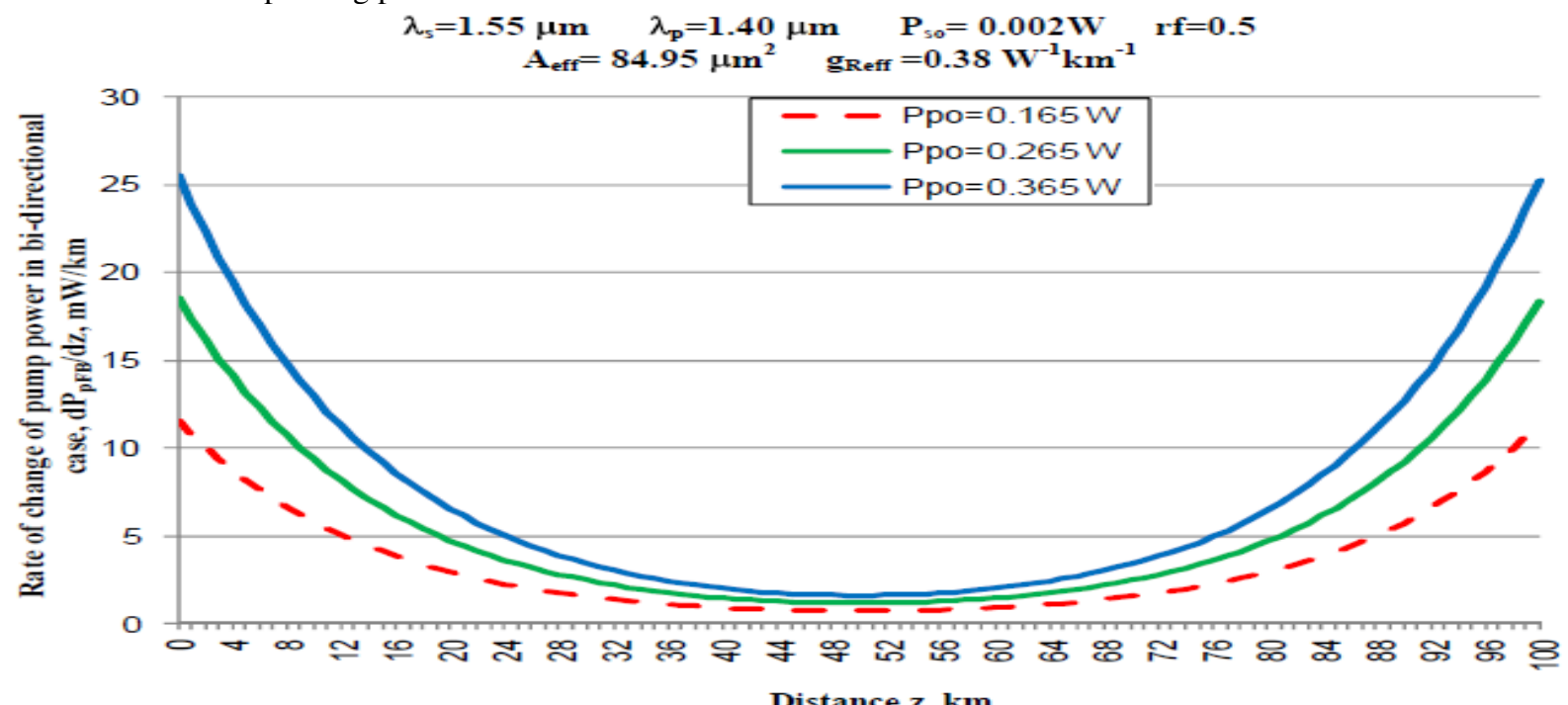

Fig. 16. Variations of rate of change of pump power in bi-directional case against variations of distance $\mathrm{z}$ at the assumed set of the operating parameters. 
International Journal of Computer Science and Network (IJCSN)

Volume 1, Issue 1, February 2012 www.ijcsn.org ISSN 2277-5420

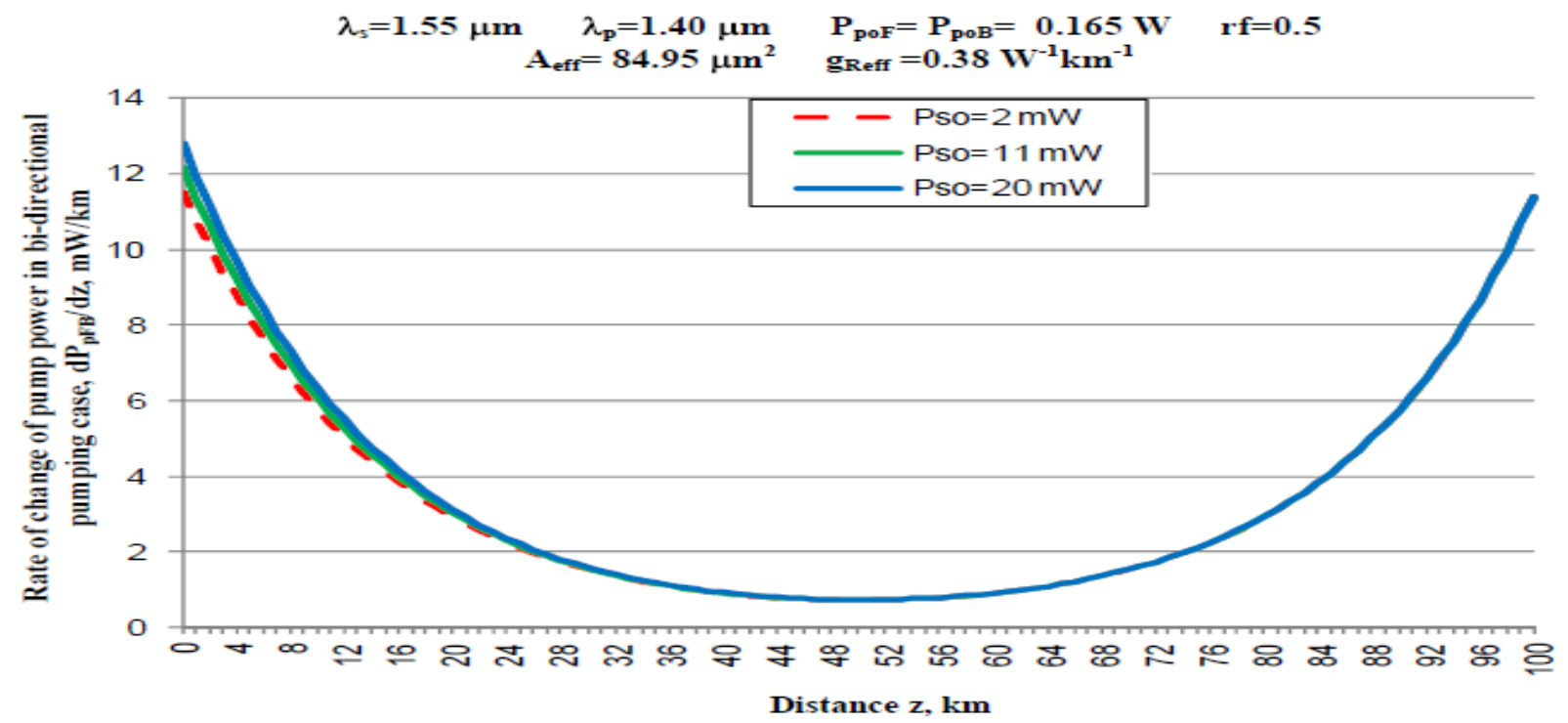

Fig. 17. Variations of rate of change of pump power in bi-directional pumping case against variations of distance $\mathrm{z}$ at the assumed set of the operating parameters.

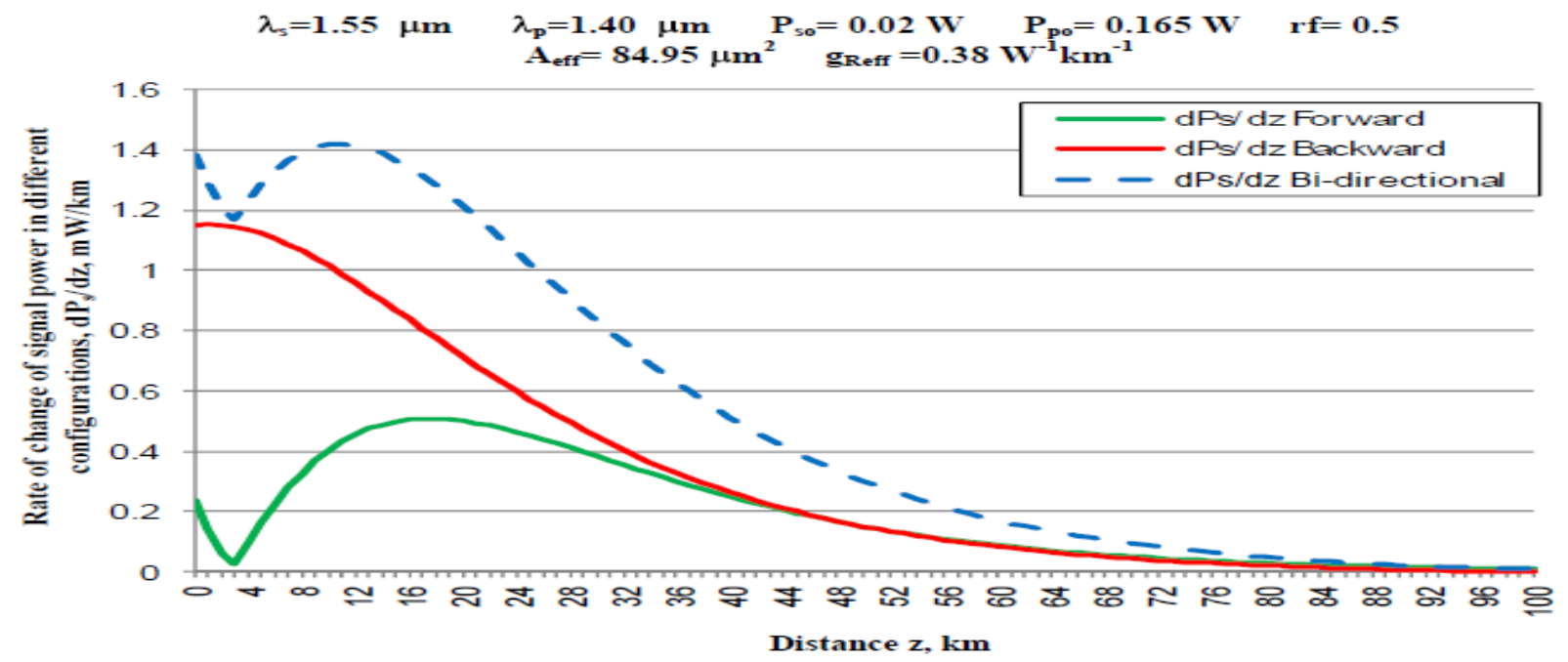

Fig. 18. Variations of rate of change of signal power in different configurations against variations of distance $\mathrm{z}$ at the assumed set of the operating parameters. 
International Journal of Computer Science and Network (IJCSN)

Volume 1, Issue 1, February 2012 www.ijcsn.org ISSN 2277-5420

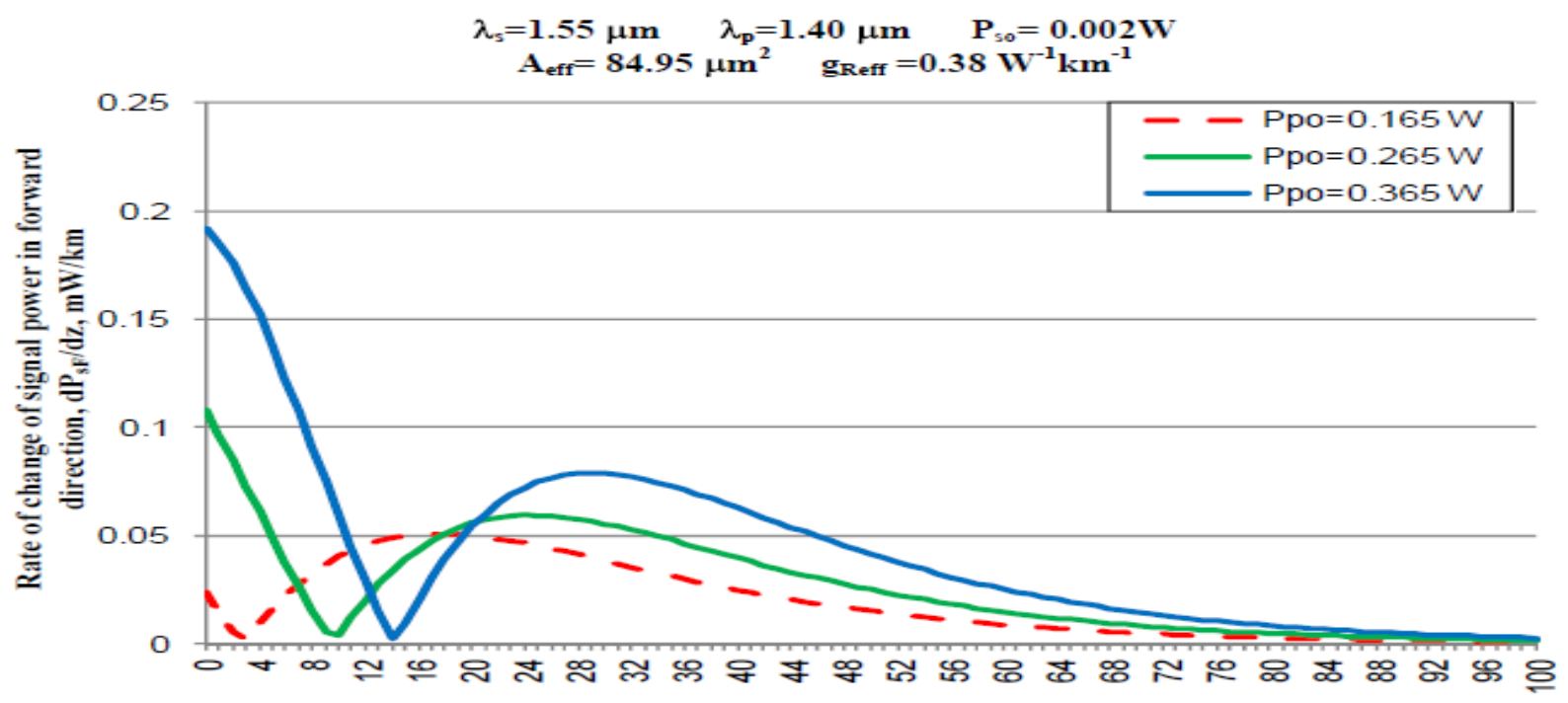

Distance z, km

Fig. 19. Variations of rate of change of signal power in forward direction against variations of distance $\mathrm{z}$ at the assumed set of the operating parameters.

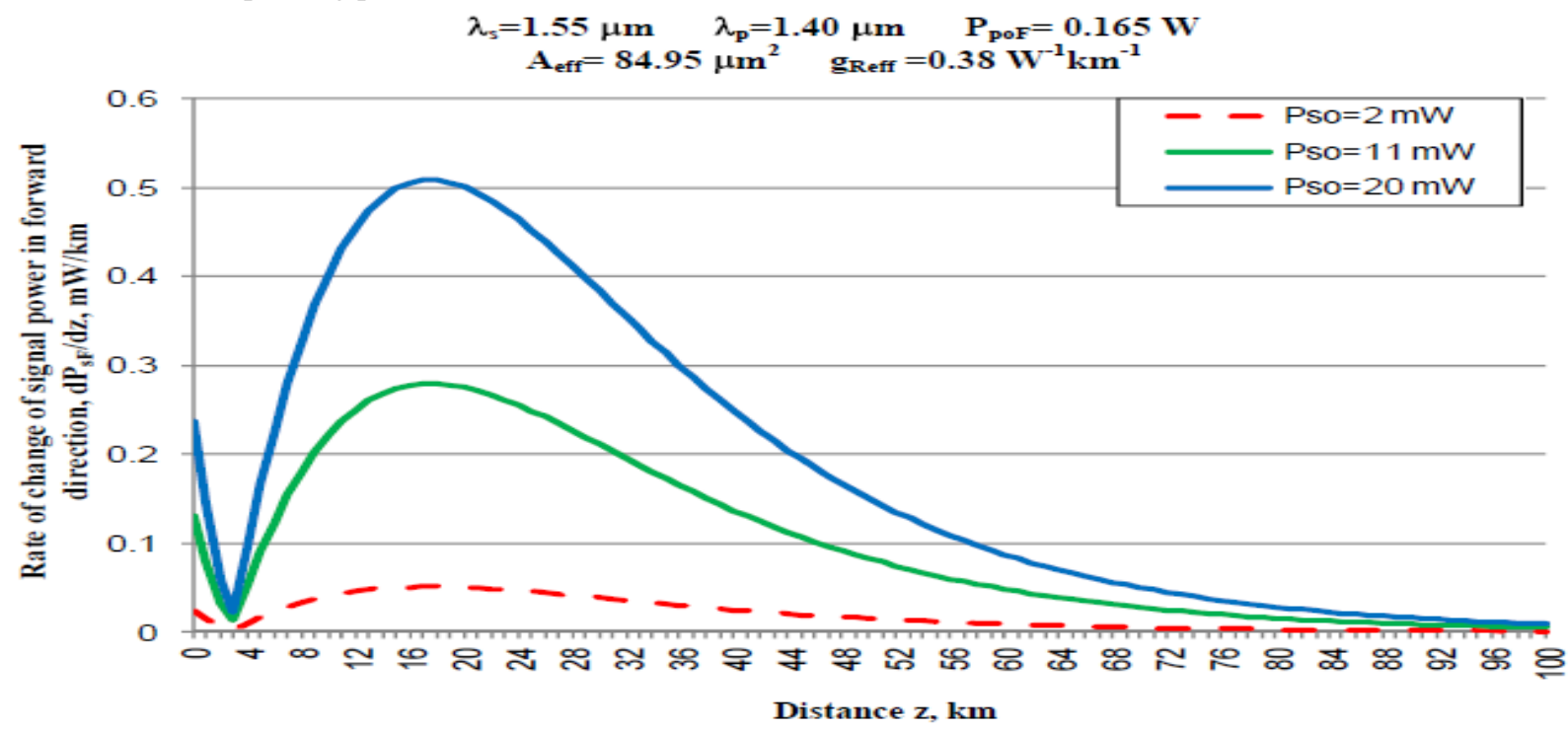

Fig. 20. Variations of rate of change of signal power in forward direction against variations of distance $\mathrm{z}$ at the assumed set of the operating parameters. 
International Journal of Computer Science and Network (IJCSN)

Volume 1, Issue 1, February 2012 www.ijcsn.org ISSN 2277-5420

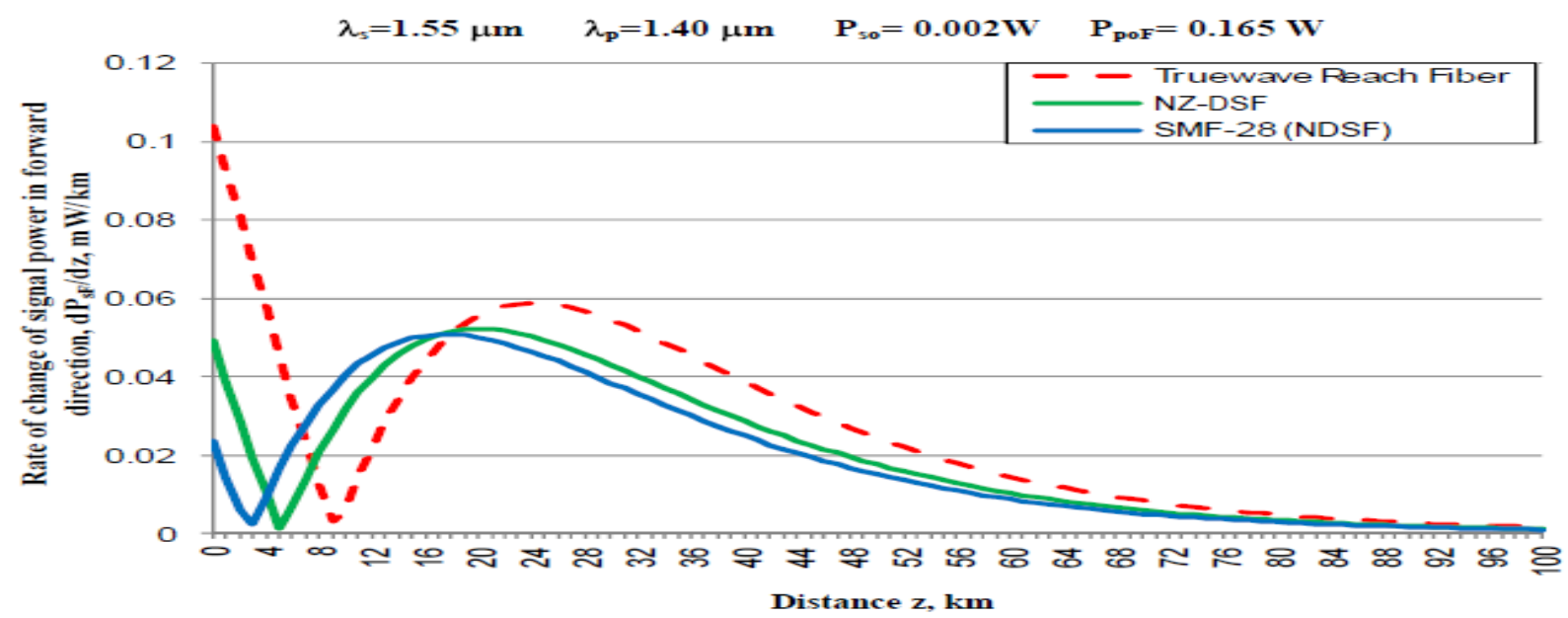

Fig. 21. Variations of rate of change of signal power in forward direction against variations of distance $\mathrm{z}$ at the assumed set of the operating parameters.

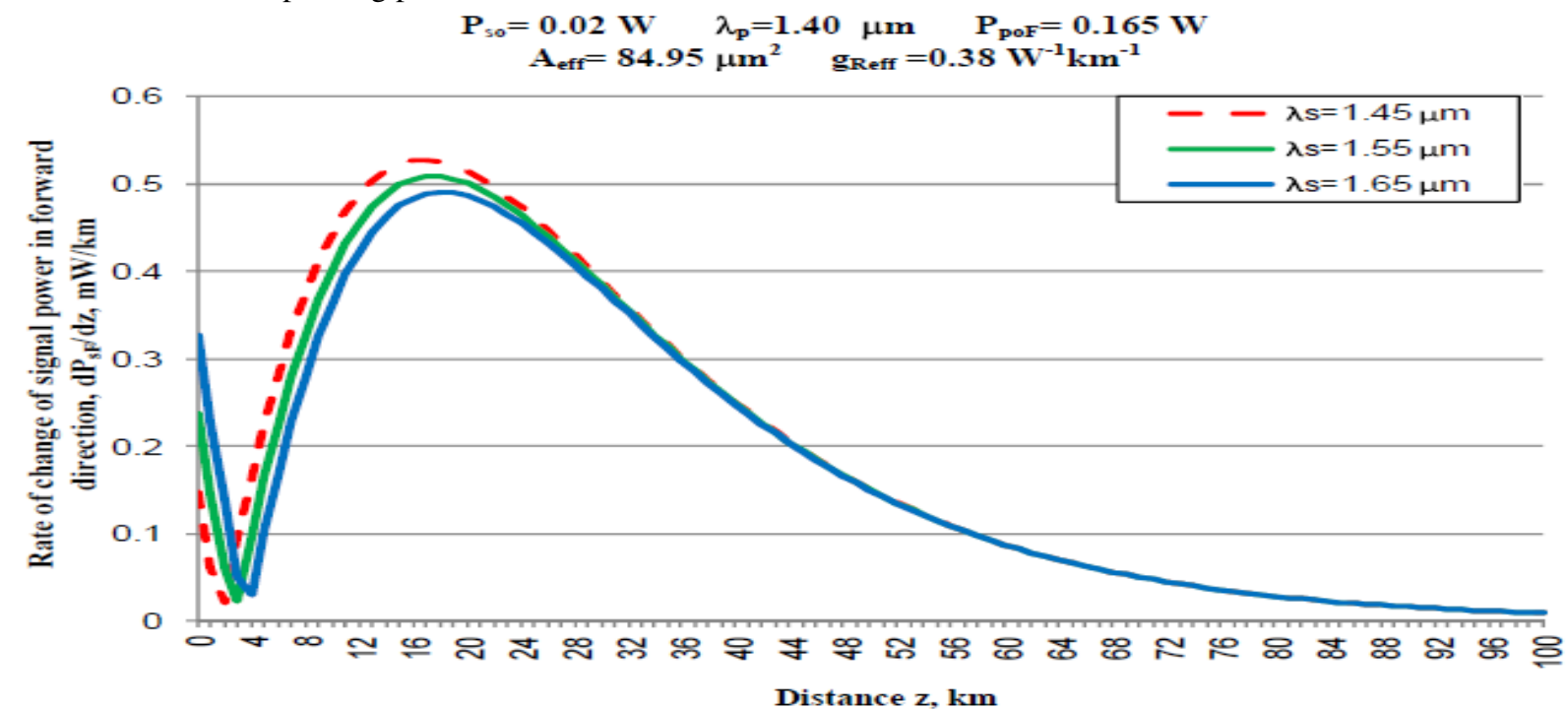

Fig. 22. Variations of rate of change of signal power in forward direction against variations of distance $\mathrm{z}$ at the assumed set of the operating parameters. 


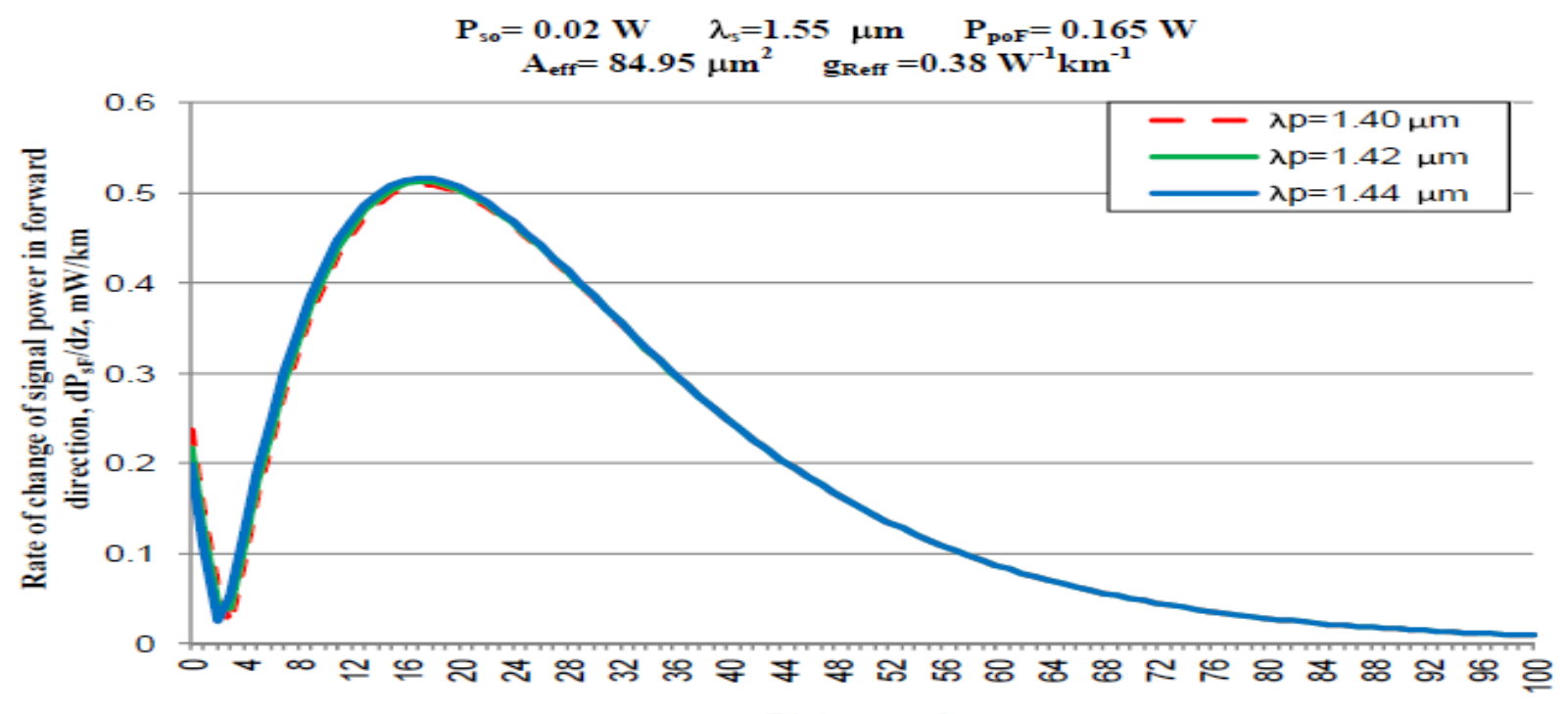

Distance z, km

Fig. 23. Variations of rate of change of signal power in forward direction against variations of distance $\mathrm{z}$ at the assumed set of the operating parameters.

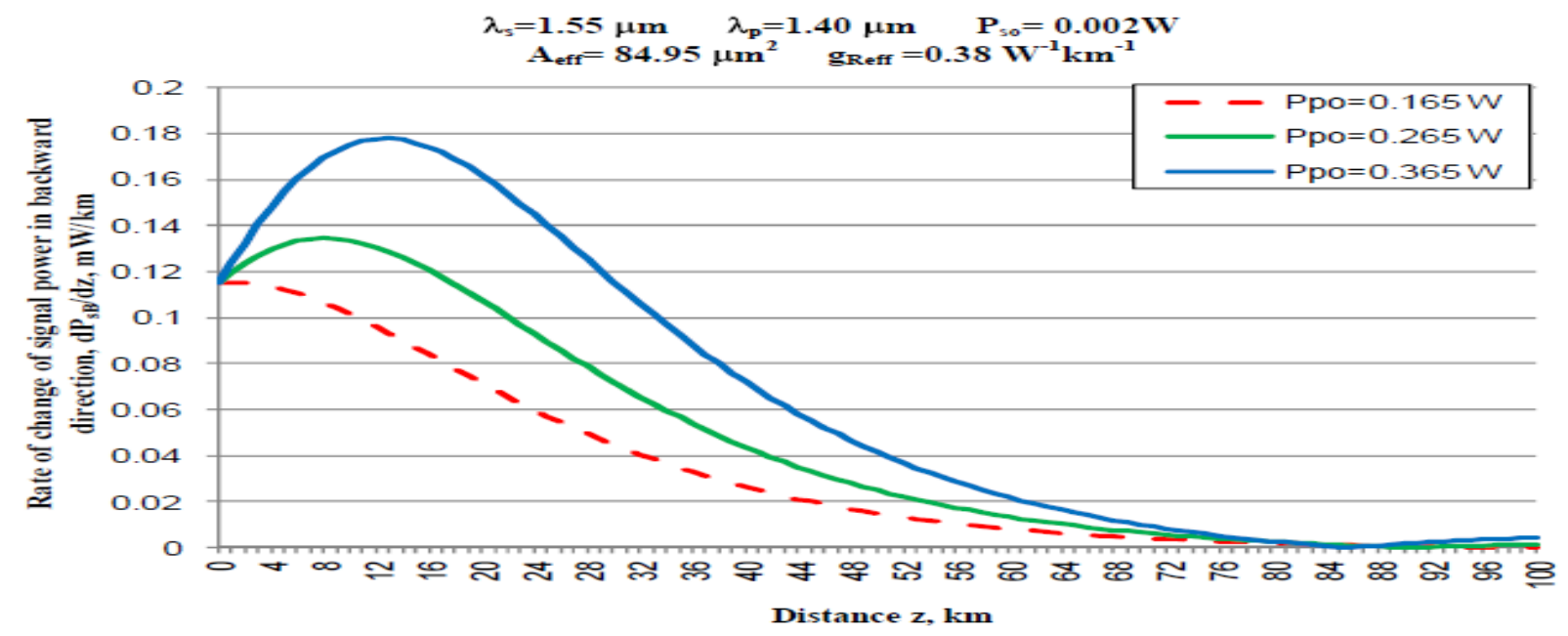

Fig. 24. Variations of rate of change of signal power in backward direction against variations of distance $\mathrm{z}$ at the assumed set of the operating parameters. 


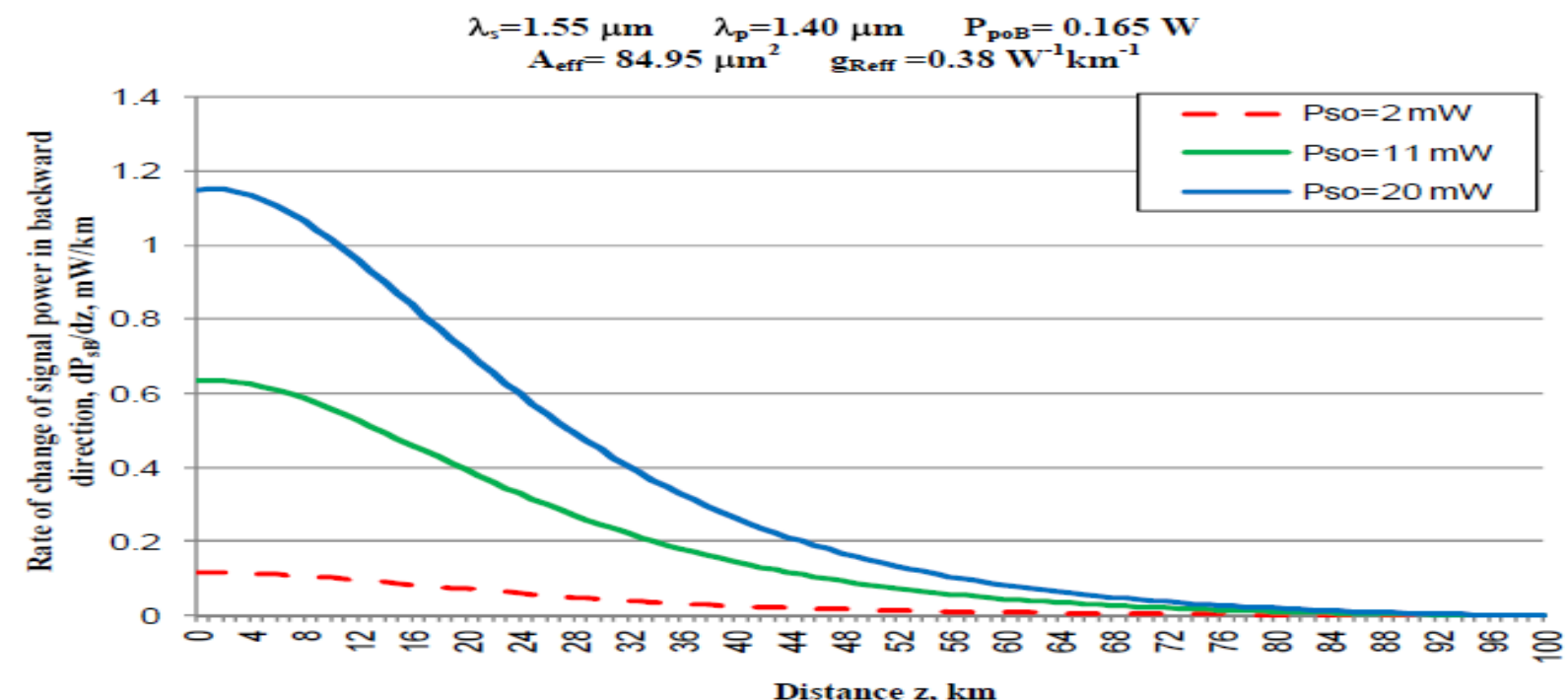

Fig. 25. Variations of rate of change of signal power in backward direction against variations of distance $\mathrm{z}$ at the assumed set of the operating parameters.

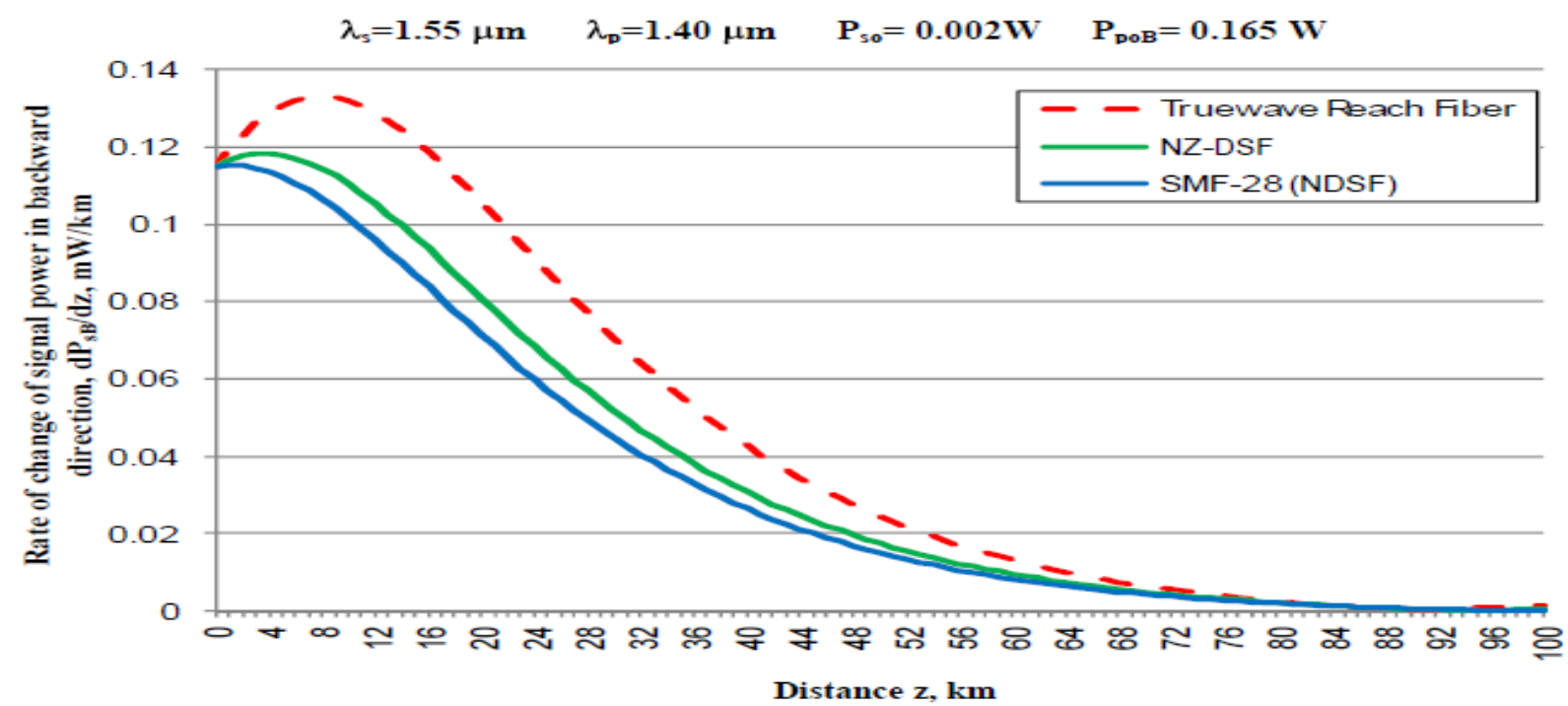

Fig. 26. Variations of rate of change of signal power in backward direction against variations of distance $\mathrm{z}$ at the assumed set of the operating parameters. 


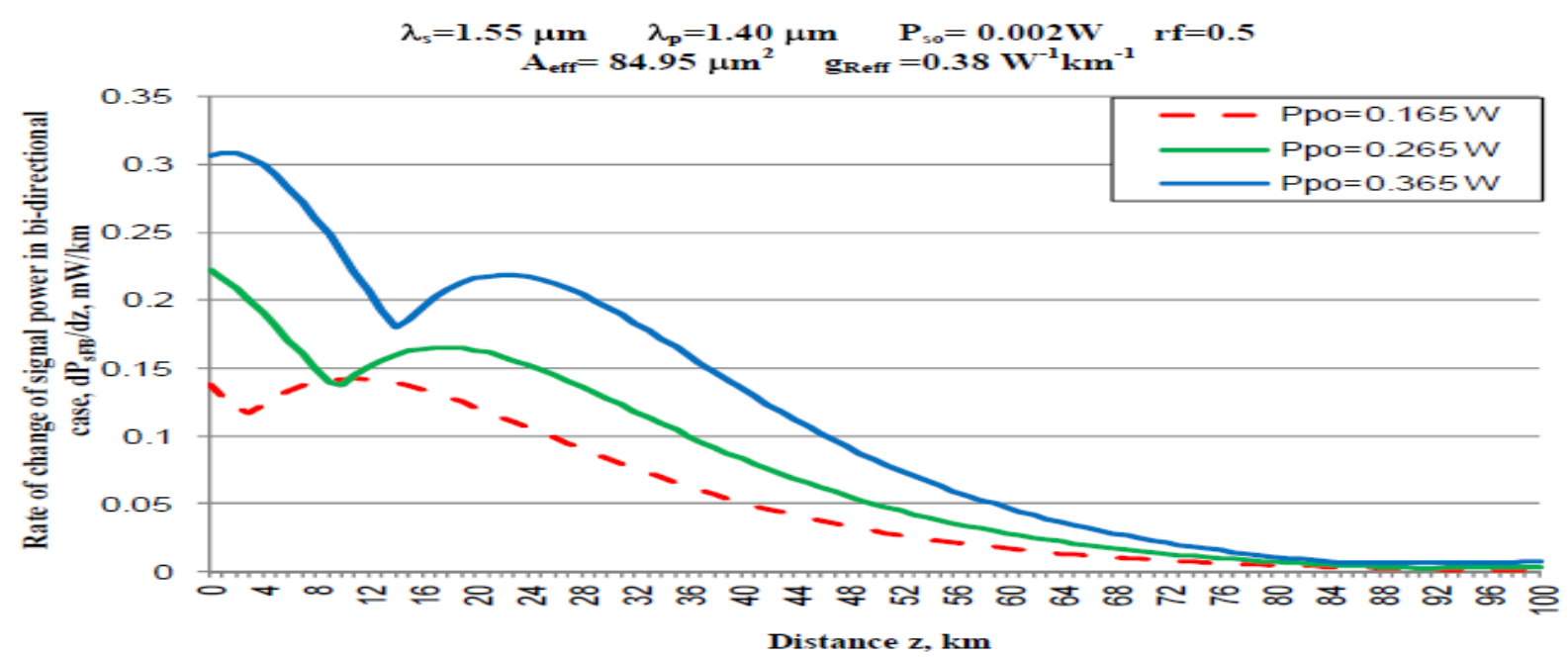

Fig. 27. Variations of rate of change of signal power in bi-directional case against variations of distance $\mathrm{z}$ at the assumed set of the operating parameters.

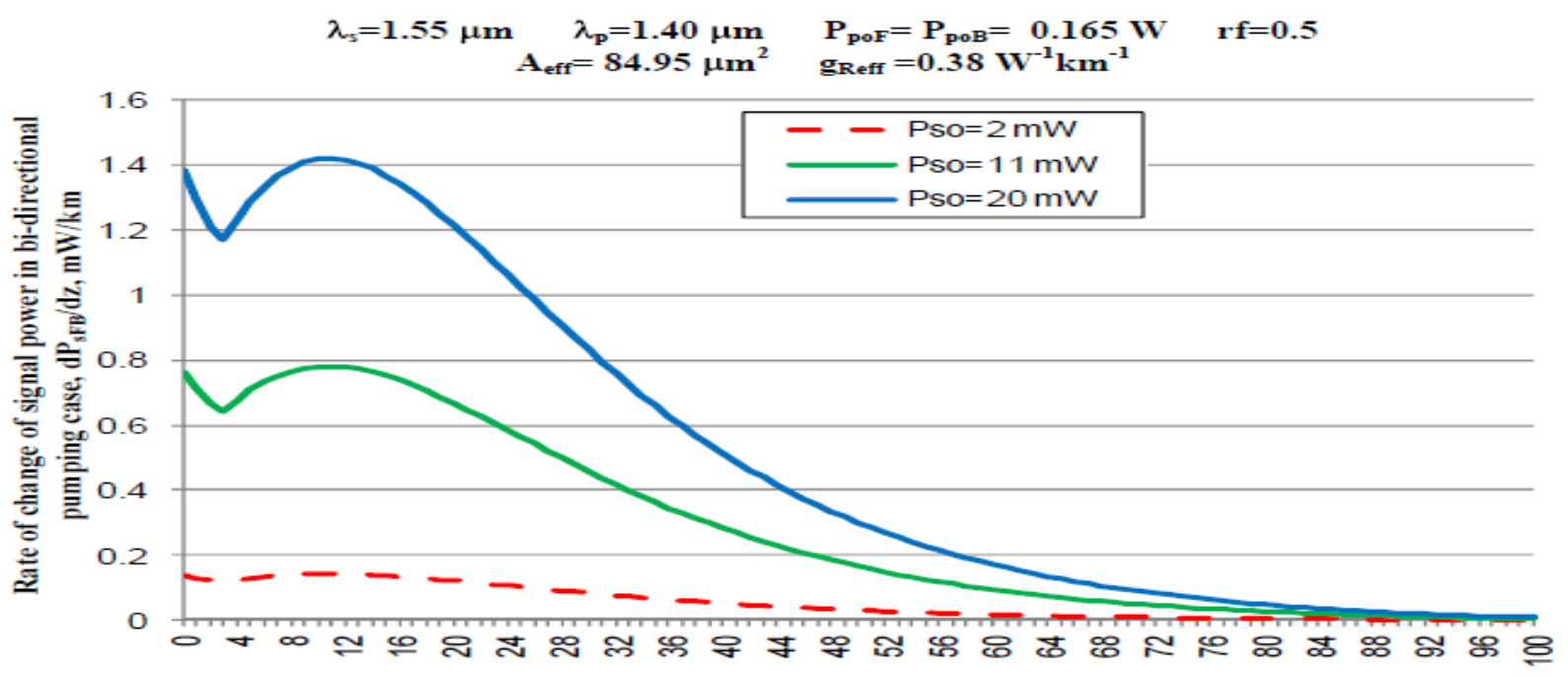

Distance z, km

Fig. 28. Variations of rate of change of signal power in bi-directional pumping case against variations of distance $\mathrm{z}$ at the assumed set of the operating parameters. 
International Journal of Computer Science and Network (IJCSN)

Volume 1, Issue 1, February 2012 www.ijcsn.org ISSN 2277-5420

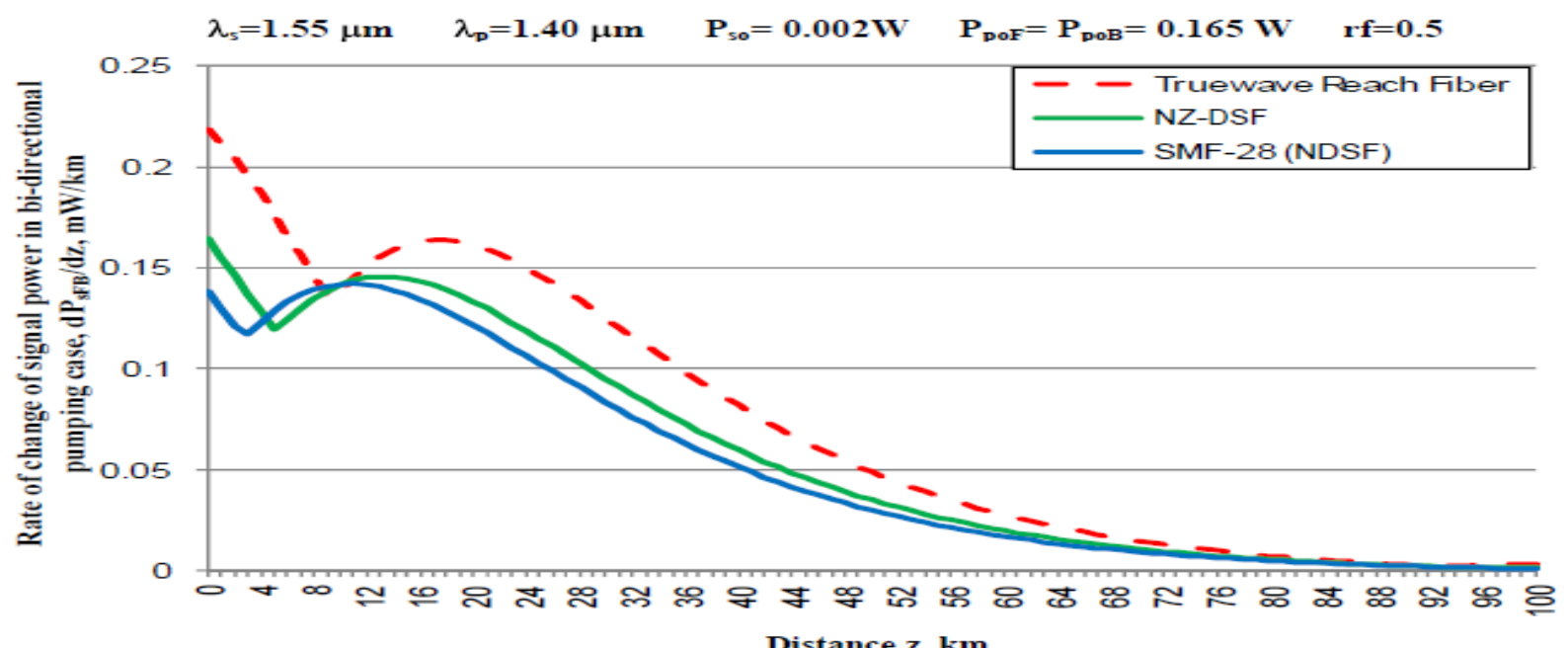

Fig. 29. Variations of rate of change of signal power in bi-directional pumping case against variations of distance $\mathrm{z}$ at the assumed set of the operating parameters.

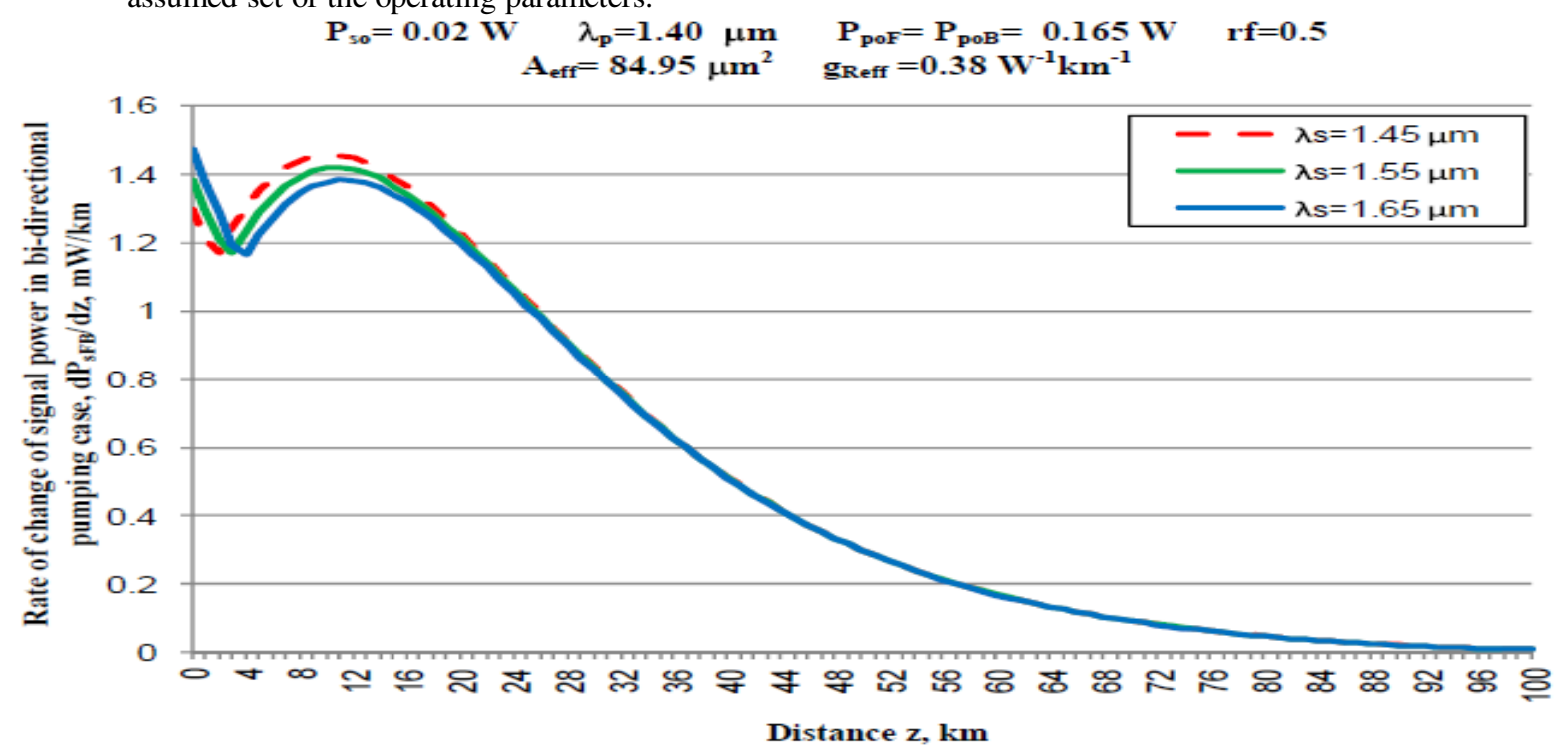

Fig. 30. Variations of rate of change of signal power in bi-directional pumping case against variations of distance $\mathrm{z}$ at the assumed set of the operating parameters. 


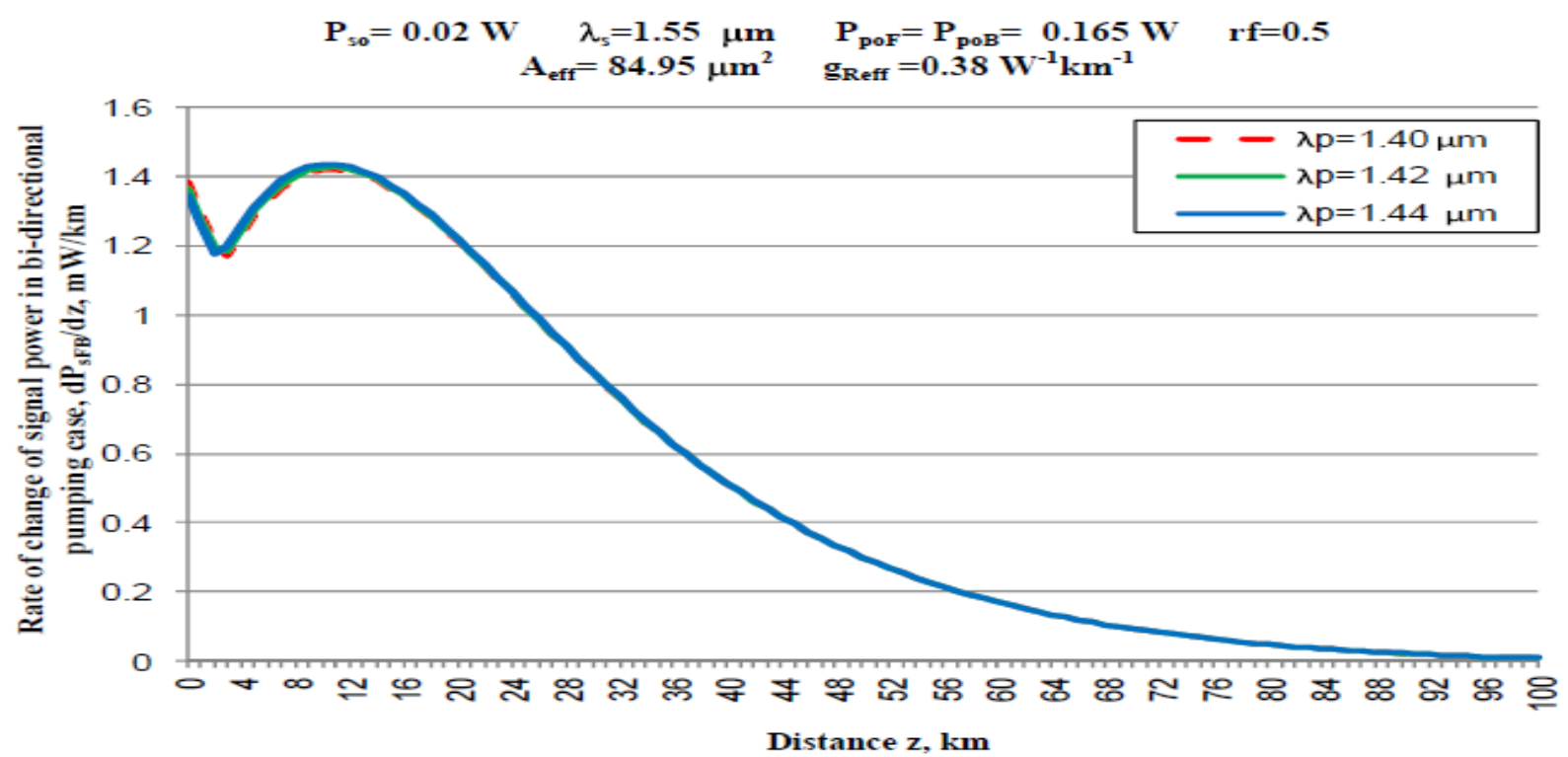

Fig. 31. Variations of rate of change of signal power in bi-directional pumping case against variations of distance $\mathrm{z}$ at the assumed set of the operating parameters.

3. 3. Variations of rate of change of pump power, $\mathbf{d P} \mathbf{p} / \mathbf{d z}$

Variation of the rate of change of pump power in different configurations; $\mathrm{dP}_{\mathrm{p}} / \mathrm{dz}$ is investigated against variations of the controlling set of parameters as displayed in Figs. (12-17). these figures clarify the following results:

a- In case of forward direction:

i. As distance $\mathrm{z}$ increases, $\mathrm{dP}_{\mathrm{pF}} / \mathrm{dz}$ decreases exponentially.

ii. For certain value of distance $z$, with increasing the initial pumping power, $\mathrm{dP}_{\mathrm{pF}} / \mathrm{dz}$ also will increase.

iii. For certain value of distance $\mathrm{z}$, with increasing the initial signal power, $\mathrm{dP}_{\mathrm{pF}} / \mathrm{dz}$ also will increase

b- In case of backward direction:

i. As distance $\mathrm{z}$ increases, $\mathrm{dP}_{\mathrm{pB}} / \mathrm{dz}$ increases exponentially.

ii. For certain value of distance $\mathrm{z}$, with increasing the initial pumping power, $\mathrm{dP}_{\mathrm{pB}} / \mathrm{dz}$ also will increase.

c- In case of bi-directional:

i. For $\mathrm{z} \leq 50 \mathrm{~km}, \mathrm{dP}_{\mathrm{pFB}} / \mathrm{dz}$ decreases exponentially, and for $\mathrm{z} \geq 50 \mathrm{~km}, \mathrm{dP}_{\mathrm{pFB}} / \mathrm{dz}$ increases exponentially.

ii. For certain value of distance $z$, with increasing the initial pumping power, $\mathrm{dP}_{\mathrm{pFB}} / \mathrm{dz}$ also will increase.

iii. For certain value of distance $\mathrm{z}$, with increasing the initial signal power, $\mathrm{dP}_{\mathrm{pFB}} / \mathrm{dz}$ also will increase.

3. 4. Variations of rate of change of signal power, $\mathrm{dP}_{\mathrm{s}} / \mathrm{dz}$
Variation of the rate of change of signal power in different configurations; $\mathrm{dP}_{\mathrm{s}} / \mathrm{dz}$ is investigated against variations of the controlling set of parameters as displayed in Figs. (18-31), these figures clarify the following results:

a- In case of forward direction:

1) For certain value of initial pumping power:

i. Initial pumping power $=0.165 \mathrm{~W}$, for $0 \leq \mathrm{z}$, $\mathrm{km} \leq 3, \mathrm{dP}_{\mathrm{sF}} / \mathrm{dz}$ decreases linearly, for $3 \leq \mathrm{z}$, $\mathrm{km} \leq 18, \mathrm{dP}_{\mathrm{sF}} / \mathrm{dz}$ increases exponentially, and for $\mathrm{z} \geq 18 \mathrm{~km}, \quad \mathrm{dP}_{\mathrm{sF}} / \mathrm{dz}$ decreases exponentially.

ii. Initial pumping power $=0.265 \mathrm{~W}$, for $0 \leq \mathrm{z}$, $\mathrm{km} \leq 10, \mathrm{dP}_{\mathrm{sF}} / \mathrm{dz}$ decreases linearly, for $10 \leq$ $\mathrm{z}, \mathrm{km} \leq 24, \mathrm{dP}_{\mathrm{sF}} / \mathrm{dz}$ increases exponentially, for $\mathrm{z} \geq 24 \mathrm{~km}, \mathrm{dP}_{\mathrm{sF}} / \mathrm{dz}$ decreases exponentially.

iii. Initial pumping power $=0.365 \mathrm{~W}$, for $0 \leq \mathrm{z}$, $\mathrm{km} \leq 14, \mathrm{dP}_{\mathrm{sF}} / \mathrm{dz}$ decreases linearly, for $14 \leq$ $\mathrm{z}, \mathrm{km} \leq 29, \mathrm{dP}_{\mathrm{sF}} / \mathrm{dz}$ increases exponentially, for $\mathrm{Z} \geq 29 \mathrm{~km}, \quad \mathrm{dP}_{\mathrm{sF}} / \mathrm{dz}$ decreases exponentially.

2) For any value of initial signal power: for $0 \leq z$, $\mathrm{km} \leq 3, \mathrm{dP}_{\mathrm{sF}} / \mathrm{dz}$ decreases linearly, for $3 \leq \mathrm{z}, \mathrm{km}$ $\leq 18, \mathrm{dP}_{\mathrm{sF}} / \mathrm{dz}$ increases exponentially, and for $\mathrm{z} \geq$ $18 \mathrm{~km}, \mathrm{dP}_{\mathrm{sF}} / \mathrm{dz}$ decreases exponentially.

3) For certain value of distance, $\mathrm{z}$ :

i. With increasing the initial signal power, $\mathrm{dP}_{\mathrm{pF}} / \mathrm{dz}$ also will increase.

ii. With increasing the initial pumping power, $\mathrm{dP}_{\mathrm{pF}} / \mathrm{dz}$ also will increase.

4) For certain value operating signal wavelength, $\lambda_{\mathrm{s}}$ :

i. $\lambda_{\mathrm{s}}=1.45 \mu \mathrm{m}$, for $0 \leq \mathrm{z}, \mathrm{km} \leq 2, \mathrm{dPs}_{\mathrm{F}} / \mathrm{dz}$ decreases linearly, for $2 \leq \mathrm{z}, \mathrm{km} \leq 17$, 
$\mathrm{dPsF} / \mathrm{dz}$ increases exponentially, and for $\mathrm{z} \geq$ $17 \mathrm{~km}, \mathrm{dPs}_{\mathrm{F}} / \mathrm{dz}$ decreases exponentially.

ii. $\lambda_{\mathrm{s}}=1.55 \mu \mathrm{m}$, for $0 \leq \mathrm{z}, \mathrm{km} \leq 3, \mathrm{dPs}_{\mathrm{F}} / \mathrm{dz}$ decreases linearly, for $3 \leq \mathrm{z}, \mathrm{km} \leq 18$, $\mathrm{dPsF} / \mathrm{dz}$ increases exponentially, and for $\mathrm{z} \geq$ $18 \mathrm{~km}, \mathrm{dPs}_{\mathrm{F}} / \mathrm{dz}$ decreases exponentially.

iii. $\lambda_{\mathrm{s}}=1.65 \mu \mathrm{m}$ for $0 \leq \mathrm{z}, \mathrm{km} \leq 4, \mathrm{dPs}_{\mathrm{F}} / \mathrm{dz}$ decreases linearly, for $4 \leq \mathrm{z}, \mathrm{km} \leq 19$, $\mathrm{dPsF} / \mathrm{dz}$ increases exponentially, and for $\mathrm{z} \geq$ $19 \mathrm{~km}, \mathrm{dPs}_{\mathrm{F}} / \mathrm{dz}$ decreases exponentially.

5) At the beginning with increasing the operating signal wavelength, $\lambda_{\mathrm{s}} \mathrm{dP}_{\mathrm{sF}} / \mathrm{dz}$ also will increase, after that $\mathrm{dP}_{\mathrm{sF}} / \mathrm{dz}$ decreases with increasing the operating signal wavelength, $\lambda_{\mathrm{s}}$.

6) For certain value operating pump wavelength, $\lambda_{\mathrm{p}}$ :

i. $\quad \lambda_{\mathrm{p}}=1.40 \mu \mathrm{m}$, for $0 \leq \mathrm{z}, \mathrm{km} \leq 3, \mathrm{dPs}_{\mathrm{F}} / \mathrm{dz}$ decreases linearly, for $3 \leq \mathrm{z}, \mathrm{km} \leq 18$, $\mathrm{dPsF} / \mathrm{dz}$ increases exponentially, and for $\mathrm{z} \geq$ $18 \mathrm{~km}, \mathrm{dPs}_{\mathrm{F}} / \mathrm{dz}$ decreases exponentially.

ii. $\lambda_{\mathrm{p}}=1.42 \mu \mathrm{m}$, for $0 \leq \mathrm{z}, \mathrm{km} \leq 2, \mathrm{dPS}_{\mathrm{F}} / \mathrm{dz}$ decreases linearly, for $2 \leq \mathrm{z}, \mathrm{km} \leq 17$, $\mathrm{dPsF} / \mathrm{dz}$ increases exponentially, and for $\mathrm{z} \geq$ $17 \mathrm{~km}, \mathrm{dPs}_{\mathrm{F}} / \mathrm{dz}$ decreases exponentially.

iii. $\lambda_{\mathrm{p}}=1.44 \mu \mathrm{m}$ for $0 \leq \mathrm{z}, \mathrm{km} \leq 1, \mathrm{dPS}_{\mathrm{F}} / \mathrm{dz}$ decreases linearly, for $1 \leq \mathrm{z}, \mathrm{km} \leq 16$, $\mathrm{dPsF} / \mathrm{dz}$ increases exponentially, and for $\mathrm{z} \geq$ $16 \mathrm{~km}, \mathrm{dPs}_{\mathrm{F}} / \mathrm{dz}$ decreases exponentially.

7) After using different media of optical fiber cable, it is indicated that the true wave reach fiber presented the best results.

b- In case of backward direction:

1) For certain value of initial pumping power:

i. Initial pumping power $=0.165 \mathrm{~mW}$, for distance $\mathrm{z} \leq 2 \mathrm{~km}, \mathrm{dP}_{\mathrm{sB}} / \mathrm{dz}$ increases exponentially, and for $\mathrm{z} \geq 2 \mathrm{~km}, \mathrm{dP}_{\mathrm{sB}} / \mathrm{dz}$ decreases exponentially.

ii. Initial pumping power $=0.265 \mathrm{~mW}$, for distance $\mathrm{z} \leq 8 \mathrm{~km}, \quad \mathrm{dP}_{\mathrm{sB}} / \mathrm{dz}$ increases exponentially, and for $\mathrm{z} \geq 8 \mathrm{~km}, \mathrm{dP}_{\mathrm{sB}} / \mathrm{dz}$ decreases exponentially.

iii. Initial pumping power $=0.365 \mathrm{~mW}$, for distance $\mathrm{z} \leq 13 \mathrm{~km}, \mathrm{dP}_{\mathrm{sB}} / \mathrm{dz}$ increases exponentially, and for $\mathrm{z} \geq 13 \mathrm{~km}, \mathrm{dP}_{\mathrm{sB}} / \mathrm{dz}$ decreases exponentially.

2) For certain value of distance $z$ :

iii. With increasing the initial pumping power, $\mathrm{dP}_{\mathrm{sB}} / \mathrm{dz}$ also will increase.

iv. With increasing the initial signal power, $\mathrm{dP}_{\mathrm{sB}} / \mathrm{dz}$ also will increase.

3) After using different media of optical fiber cable, it is indicated that the true wave reach fiber presented the best results.

c- In case of bi-directional:

1) For certain value of initial pumping power:

i. Initial pumping power $=0.165 \mathrm{~W}$, for $0 \leq \mathrm{z}$, $\mathrm{km} \leq 3, \mathrm{dP}_{\mathrm{sFB}} / \mathrm{dz}$ decreases linearly, for $3 \leq \mathrm{z}$, $\mathrm{km} \leq 11, \mathrm{dP}_{\mathrm{sFB}} / \mathrm{dz}$ increases exponentially, and for $\mathrm{z} \geq 11 \mathrm{~km}, \mathrm{dP}_{\mathrm{sFB}} / \mathrm{dz}$ decreases exponentially.

ii. Initial pumping power $=0.265 \mathrm{~W}$, for $0 \leq \mathrm{z}$, $\mathrm{km} \leq 10, \mathrm{dP}_{\mathrm{sFB}} / \mathrm{dz}$ decreases linearly, for $10 \leq$ $\mathrm{z}, \mathrm{km} \leq 18, \mathrm{dP}_{\mathrm{sFB}} / \mathrm{dz}$ increases exponentially, for $\mathrm{z} \geq 18 \mathrm{~km}, \quad \mathrm{dP}_{\mathrm{sFB}} / \mathrm{dz}$ decreases exponentially.

iii. Initial pumping power $=0.365 \mathrm{~W}$, for $0 \leq \mathrm{z}$, $\mathrm{km} \leq 14, \mathrm{dP}_{\mathrm{sFB}} / \mathrm{dz}$ decreases linearly, for $14 \leq$ $\mathrm{z}, \mathrm{km} \leq 22, \mathrm{dP}_{\mathrm{sFB}} / \mathrm{dz}$ increases exponentially, for $\mathrm{z} \geq 22 \mathrm{~km}, \quad \mathrm{dP}_{\mathrm{sFB}} / \mathrm{dz}$ decreases exponentially.

2) For any value of initial signal power: for $0 \leq z$, $\mathrm{km} \leq 3, \mathrm{dP}_{\mathrm{sFB}} / \mathrm{dz}$ decreases linearly, for $3 \leq \mathrm{z}, \mathrm{km}$ $\leq 11, \mathrm{dP}_{\mathrm{SFB}} / \mathrm{dz}$ increases exponentially, and for $\mathrm{z}$ $\geq 11 \mathrm{~km}, \mathrm{dP}_{\mathrm{sFB}} / \mathrm{dz}$ decreases exponentially.

3) For certain value of distance, $z$ :

i. With increasing the initial signal power, $\mathrm{dP}_{\mathrm{sFB}} / \mathrm{dz}$ also will increase.

ii. With increasing the initial pumping power, $\mathrm{dP}_{\mathrm{SFB}} / \mathrm{dz}$ also will increase.

4) For certain value operating signal wavelength, $\lambda_{\mathrm{S}}$ :

i. $\lambda_{\mathrm{s}}=1.45 \mu \mathrm{m}$, for $0 \leq \mathrm{z}, \mathrm{km} \leq 2, \mathrm{dP}_{\mathrm{sFB}} / \mathrm{dz}$ decreases linearly, for $2 \leq \mathrm{z}, \mathrm{km} \leq 10$, $\mathrm{dP}_{\mathrm{SFB}} / \mathrm{dz}$ increases exponentially, and for $\mathrm{z} \geq$ $10 \mathrm{~km}, \mathrm{dP}_{\mathrm{sFB}} / \mathrm{dz}$ decreases exponentially.

ii. $\lambda_{\mathrm{s}}=1.55 \mu \mathrm{m}$, for $0 \leq \mathrm{z}, \mathrm{km} \leq 3, \mathrm{dP}_{\mathrm{sFB}} / \mathrm{dz}$ decreases linearly, for $3 \leq \mathrm{z}, \mathrm{km} \leq 11$, $\mathrm{dP}_{\mathrm{SFB}} / \mathrm{dz}$ increases exponentially, and for $\mathrm{z} \geq$ $11 \mathrm{~km}, \mathrm{dP}_{\mathrm{sFB}} / \mathrm{dz}$ decreases exponentially.

iii. $\lambda_{\mathrm{s}}=1.65 \mu \mathrm{m}$ for $0 \leq \mathrm{z}, \mathrm{km} \leq 4, \mathrm{dP}_{\mathrm{sFB}} / \mathrm{dz}$ decreases linearly, for $4 \leq \mathrm{z}, \mathrm{km} \leq 12$, $\mathrm{dP}_{\mathrm{SFB}} / \mathrm{dz}$ increases exponentially, and for $\mathrm{z} \geq$ $12 \mathrm{~km}, \mathrm{dP}_{\mathrm{sFB}} / \mathrm{dz}$ decreases exponentially.

5) At the beginning with increasing the operating signal wavelength, $\lambda_{\mathrm{s}} \mathrm{dP}_{\mathrm{FB}} / \mathrm{dz}$ also will increase, after that $\mathrm{dPs}_{\mathrm{FB}} / \mathrm{dz}$ decreases with increasing the operating signal wavelength, $\lambda_{\mathrm{s}}$.

6) For certain value operating pump wavelength, $\lambda_{\mathrm{p}}$ :

i. $\lambda_{\mathrm{p}}=1.40 \mu \mathrm{m}$, for $0 \leq \mathrm{z}, \mathrm{km} \leq 3, \mathrm{dP}_{\mathrm{sFB}} / \mathrm{dz}$ decreases linearly, for $3 \leq \mathrm{z}, \mathrm{km} \leq 11$, $\mathrm{dP}_{\mathrm{sFB}} / \mathrm{dz}$ increases exponentially, and for $\mathrm{z} \geq$ $11 \mathrm{~km}, \mathrm{dP}_{\mathrm{sFB}} / \mathrm{dz}$ decreases exponentially.

ii. $\lambda_{\mathrm{p}}=1.42 \mu \mathrm{m}$, for $0 \leq \mathrm{z}, \mathrm{km} \leq 2, \mathrm{dP}_{\mathrm{sFB}} / \mathrm{dz}$ decreases linearly, for $2 \leq \mathrm{z}, \mathrm{km} \leq 11$, $\mathrm{dP}_{\mathrm{sFB}} / \mathrm{dz}$ increases exponentially, and for $\mathrm{z} \geq$ $11 \mathrm{~km}, \mathrm{dP}_{\mathrm{sFB}} / \mathrm{dz}$ decreases exponentially.

iii. $\lambda_{\mathrm{p}}=1.44 \mu \mathrm{m}$ for $0 \leq \mathrm{z}, \mathrm{km} \leq 1, \mathrm{dP}_{\mathrm{sFB}} / \mathrm{dz}$ decreases linearly, for $1 \leq \mathrm{z}, \mathrm{km} \leq 11$, $\mathrm{dP}_{\mathrm{SFB}} / \mathrm{dz}$ increases exponentially, and for $\mathrm{z} \geq$ $11 \mathrm{~km}, \mathrm{dP}_{\mathrm{sFB}} / \mathrm{dz}$ decreases exponentially. After using different media of optical fiber cable, it is indicated that the true wave reach fiber presented the best results.

\section{Conclusions}

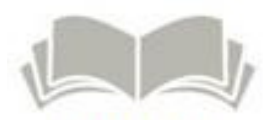


In a summary, The points of discussion indicated all the operating design parameters of multiplexing/demultiplexing based distributed optical fiber Raman amplifier device, such as input signal power, input pumping power, operating signal wavelength, operating pump wavelength, and different fiber link media. Therefore we have deeply investigated multiplexing/demultiplexing based distributed optical fiber Raman amplifier over wide range of the affecting parameters. As well as we have taken into account signal power, pumping power, and the rate of change of both signal power and pumping power along the transmission distance within the variety of operating signal wavelength, operation pumping wavelength, input signal power, input pumping power, different fiber link media, and finally Raman gain efficiency for all pumping direction configurations such as forward, backward, and bidirectional pumping. The effects of the verity of these parameters are mentioned in details in the previous section of the results and performance analysis. After using different media of optical fiber cable, it is indicated that the true wave reach fiber presented the best candidate media for the highest signal transmission performance efficiency.

\section{REFERENCES}

[1] Maan M. Shaker, Mahmood Sh. Majeed, and Raid W. Daoud, "Functioning the Intelligent Programming to find Minimum Dispersion Wavelengths," Wseas Transactions on Communications, Vol. 8, No. 2, pp. 237-248, 2009.

[2] M. V. Raghavendra, and P. L. H. Vara Prasad, "Estimation of Optical Link Length for Multi Haul Applications," International Journal of Engineering Science and Technology, Vol. 2, No. 6, pp. 1485-1491, 2010.

[3] Abd El-Naser A. Mohammed, and Ahmed Nabih Zaki Rashed, "Comparison Performance Evolution of Different Transmission Techniques With Bi-directional Distributed Raman Gain Amplification Technique in High Capacity Optical Networks," International Journal of Physical Sciences, Vol. 5, No. 5, pp. 484-495, 2010.

[4] Ming-Jun Li, and Daniel A. Nolan, "Optical Transmission Fiber Design Evolution,” J. Lightwave Technol., Vol. 26, No. 9, pp. 1079-1092, 2008.

[5] Abd El-Naser A. Mohammed, Gaber E. S. M. El-Abyad, Abd El-Fattah A. Saad, and Ahmed Nabih Zaki Rashed, "Applications of Conventional and A thermal Arrayed Waveguide Grating (AWG) Module in Active and Passive Optical Networks (PONs)," International Journal of Computer Theory and Engineering (IJCTE), Vol. 1, No. 3, pp. 290-298, 2009.

[6] ITU-T Recommendation G.652, "Characteristics of Single Mode Optical Fiber and Cable," ITU-T Study Group, pp. 114, 2009.

[7] Abd El-Naser A. Mohammed, Abd El-Fattah A. Saad, and Ahmed Nabih Zaki Rashed and Mahomud M. Eid, "Characteristics of Multi-Pumped Raman Amplifiers in Dense Wavelength Division Multiplexing (DWDM) Optical Access Networks," IJCSNS International Journal of Computer Science and Network Security, Vol. 9, No. 2, pp. 277-284, 2009.
[8] S. Shahi, S. W. Harun, K. Dimyati, and H. Ahmad, "Brillouin Fiber Laser With Significantly Reduced Gain Medium Length Operating in L Band Region," Progress In Electromagnetics Research Letters, Vol. 8, No. 3, pp. 143149, 2009.

[9] A. Banerjee, "New Approach to Design Digitally Tunable Optical Fiber System for Wavelength Selective Switching Based Optical Networks," Progress In Electromagnetics Research Letters, Vol. 9, No. 2, pp. 93-100, 2009.

[10] Abd El-Naser A. Mohammed and Ahmed Nabih Zaki Rashed, "Ultra Wide Band (UWB) of Optical Fiber Raman Amplifiers in Advanced Optical Communication Networks," Journal of Media and Communication Studies (IJMCS), Vol. 1, No. 4, pp. 56-78, 2009.

[11] S. Makoui, M. Savadi-Oskouei, A. Rostami, and Z. D. Koozehkanani, "Dispersion Flattened Optical Fiber Design for Large Bandwidth and High Speed Optical Communications Using Optimization Technique," Progress In Electromagnetics Research B, Vol. 13, No. 3, pp. 21-40, 2009.

[12] M. El Mashade, M. B. and M. N. Abdel Aleem, "Analysis of Ultra Short Pulse Propagation in Nonlinear Optical Fiber," Progress In Electromagnetics Research B, Vol. 12, No. 3, pp. 219-241, 2009.

[13] Abd El Naser A. Mohammed, Mohamed Metawe'e, Ahmed Nabih Zaki Rashed, and Mahmoud M. A. Eid, "Distributed Optical Raman Amplifiers in Ultra High Speed Long Haul Transmission Optical Fiber Telecommunication Networks," International Journal of Computer and Network Security (IJCNS), Vol. 1, No.1, pp. 1-8, 2009.

[14] S. Raghuawansh, V. Guta, V. Denesh, and S. Talabattula, "Bi-directional Optical Fiber Transmission Scheme Through Raman Amplification: Effect of Pump Depletion," Journal of Indian Institute of Science, Vol. 5, No. 2, pp. 655-665, 2006.

[15] C.J.S. de Matos, K.P. Hansen and J.R. Taylor, "Experimental Characterization of Raman Gain Efficiency of Holey Fiber," Electronics Letters, Vol. 39, No.5, pp. 424, Mar. 2003.

[16] E. S. Son, J. H. Lee, and Y. C. Chung, "Statistics of Polarization-Dependent Gain in Fiber Raman Amplifiers," J. Lightwave Technol., Vol. 23, No.3, pp. 1219-1226, Mar. 2005. 